Chapman University

Chapman University Digital Commons

Pharmacy Faculty Articles and Research

School of Pharmacy

2004

\title{
Hepatitis B Vaccination for Patients with Chronic Renal Failure
}

Robert J. Schroth

University of Manitoba

Carol A. Hitchon

University of Manitoba

Julia Uhanova

University of Manitoba

Ayman M. Noreddin

Chapman University, noreddin@chapman.edu

Shayne P. Taback

University of Manitoba

See next page for additional authors

Follow this and additional works at: http://digitalcommons.chapman.edu/pharmacy_articles

Part of the Pharmacy and Pharmaceutical Sciences Commons

\section{Recommended Citation}

Schroth R, Hitchon C, Zacharias J, Uhanovaj J, Noreddin A, Tabacks P, Moffatt M, Zacharias JM. Hepatitis B vaccination for patients with chronic renal failure. Cochrane Database Syst Rev. 3:CD003775, 2004. doi: 10.1002/14651858.CD003775.pub2

This Article is brought to you for free and open access by the School of Pharmacy at Chapman University Digital Commons. It has been accepted for inclusion in Pharmacy Faculty Articles and Research by an authorized administrator of Chapman University Digital Commons. For more information, please contact laughtin@chapman.edu. 


\section{Hepatitis B Vaccination for Patients with Chronic Renal Failure}

Comments

This article was originally published in Cochrane Database of Systematic Reviews in 2004. DOI: 10.1002/

14651858.CD003775.pub2

\section{Copyright}

Cochrane Collaboration

\section{Authors}

Robert J. Schroth, Carol A. Hitchon, Julia Uhanova, Ayman M. Noreddin, Shayne P. Taback, Michael Moffatt, and James M. Zacharias 


\section{(E) Cochrane Library}

Cochrane Database of Systematic Reviews

\section{Hepatitis B vaccination for patients with chronic renal failure (Review)}

Schroth RJ, Hitchon CA, Uhanova J, Noreddin AM, Taback SP, Moffatt M, Zacharias JM

Schroth RJ, Hitchon CA, Uhanova J, Noreddin AM, Taback SP, Moffatt M, Zacharias JM.

Hepatitis $B$ vaccination for patients with chronic renal failure.

Cochrane Database of Systematic Reviews 2004, Issue 3. Art. No.: CD003775.

DOI: 10.1002/14651858.CD003775.pub2.

www.cochranelibrary.com 
TABLE OF CONTENTS

HEADER . . . . . . . . . . . . . . . . . . . . . . . . . . . . . . . . . . . . . . . . 1

ABSTRACT . . . . . . . . . . . . . . . . . . . . . . . . . . . . . . . . . . . . . . .

PLAIN LANGUAGE SUMMARY . . . . . . . . . . . . . . . . . . . . . . . . . . . . . . . . . . . .

BACKGROUND . . . . . . . . . . . . . . . . . . . . . . . . . . . . . . . . . . . . . 2

OBJECTIVES . . . . . . . . . . . . . . . . . . . . . . . . . . . . . . . . . . . . . . . . . . . . . . .

METHODS . . . . . . . . . . . . . . . . . . . . . . . . . . . . . . . . . . . . . .

RESULTS . . . . . . . . . . . . . . . . . . . . . . . . . . . . . . . . . . . . . . . 5

DISCUSSION . . . . . . . . . . . . . . . . . . . . . . . . . . . . . . . . . . . . .

AUTHORS' CONCLUSIONS . . . . . . . . . . . . . . . . . . . . . . . . . . . . . . . . . . . . . . . . .

ACKNOWLEDGEMENTS . . . . . . . . . . . . . . . . . . . . . . . . . . . . . . . . . 9

REFERENCES . . . . . . . . . . . . . . . . . . . . . . . . . . . . . . . . . . . . . . 9

CHARACTERISTICS OF STUDIES . . . . . . . . . . . . . . . . . . . . . . . . . . . . . . . . . 12

DATA AND ANALYSES . . . . . . . . . . . . . . . . . . . . . . . . . . . . . . . . . . . . . . . . . . . . . . . . .

Analysis 1.1. Comparison 1 Plasma vaccine versus placebo, Outcome 1 Seroconversion to anti-HBs. . . . . . . . 19

Analysis 1.2. Comparison 1 Plasma vaccine versus placebo, Outcome 2 Full and partial anti-HBs seroconversion. . . 19

Analysis 1.3. Comparison 1 Plasma vaccine versus placebo, Outcome 3 Hepatitis B virus infection. . . . . . . . 20

Analysis 1.4. Comparison 1 Plasma vaccine versus placebo, Outcome 4 Adverse events. . . . . . . . . . . . . 20

Analysis 1.5. Comparison 1 Plasma vaccine versus placebo, Outcome 5 Deaths. . . . . . . . . . . . . . . 21

Analysis 1.6. Comparison 1 Plasma vaccine versus placebo, Outcome 6 Sensitivity analysis for hepatitis B virus (HBV) infection excluding Stevens 1984. . . . . . . . . . . . . . . . . . . . . . . . . . . . . . . 22

Analysis 2.1. Comparison 2 Recombinant vaccine versus plasma vaccine, Outcome 1 Anti-HBs seroconversion. . . . 22

Analysis 2.2. Comparison 2 Recombinant vaccine versus plasma vaccine, Outcome 2 Full and partial seroconversion to anti-HBs.

Analysis 2.3. Comparison 2 Recombinant vaccine versus plasma vaccine, Outcome 3 Sensitivity analysis for anti-HBs seroconversion - combining both recombinant arms of Seaworth 1988.

Analysis 2.4. Comparison 2 Recombinant vaccine versus plasma vaccine, Outcome 4 Sensitivity analysis for anti-HBs seroconversion (excluding the low dose recombinant arm of Seaworth 1988).

Analysis 3.1. Comparison 3 Reinforced recombinant vaccination series versus primary recombinant vaccination series,

Outcome 1 Seroconversion to anti-HBs. . . . . . . . . . . . . . . . . . . . . . . . . . 25

ADDITIONAL TABLES . . . . . . . . . . . . . . . . . . . . . . . . . . . . . . . . . . . 25

APPENDICES . . . . . . . . . . . . . . . . . . . . . . . . . . . . . . . . . . . . . . 27

WHAT'S NEW . . . . . . . . . . . . . . . . . . . . . . . . . . . . . . . . . . . . . . . . . 29

HISTORY . . . . . . . . . . . . . . . . . . . . . . . . . . . . . . . . . . . . . . . . . . . . . . .

CONTRIBUTIONS OF AUTHORS . . . . . . . . . . . . . . . . . . . . . . . . . . . . . . . . . . . . . . . .

DECLARATIONS OF INTEREST . . . . . . . . . . . . . . . . . . . . . . . . . . . . . . . . . . . . . . . .

SOURCES OF SUPPORT . . . . . . . . . . . . . . . . . . . . . . . . . . . . . . . . . . . . . . . . . . .

INDEX TERMS . . . . . . . . . . . . . . . . . . . . . . . . . . . . . . . . . . . . 30

Hepatitis B vaccination for patients with chronic renal failure (Review)

Copyright $\odot 2009$ The Cochrane Collaboration. Published by John Wiley \& Sons, Ltd. 


\title{
[Intervention Review]
}

\section{Hepatitis B vaccination for patients with chronic renal failure}

\author{
Robert J Schroth ${ }^{2}$, Carol A Hitchon ${ }^{3}$, Julia Uhanova ${ }^{4}$, Ayman M Noreddin ${ }^{5}$, Shayne P Taback ${ }^{6}$, Michael Moffatt ${ }^{7}$, James M Zacharias
}

${ }^{1}$ Section of Nephrology, University of Manitoba, Winnipeg, Canada. ${ }^{2}$ Dental Diagnostic \& Surgical Sciences, University of Manitoba D341-Faculty of Dentistry, Winnipeg Manitoba, Canada. ${ }^{3}$ Internal Medicine, University of Manitoba RR149 Rehabilitation Hospital, Winnipeg Manitoba, Canada. ${ }^{4}$ Internal Medicine, University of Manitoba 803B John Buhler Research Centre, Winnipeg Manitoba, Canada. ${ }^{5}$ Medical Microbiology, Faculty of Medicine, University of Manitoba, Winnipeg, Canada. ${ }^{6}$ Department of Pediatrics and Child Health, University of Manitoba, Winnipeg, Canada. ${ }^{7}$ Research \& Applied Learning, Winnipeg Regional Health Authority, Winnipeg, Canada

Contact address: James M Zacharias, Section of Nephrology, University of Manitoba, Ge441B - 820 Sherbrook St, Health Sciences Centre, Winnipeg, Manitoba, R3A 1R9, Canada. jzacharias@hsc.mb.ca.

Editorial group: Cochrane Hepato-Biliary Group.

Publication status and date: Edited (no change to conclusions), published in Issue 1, 2009.

Review content assessed as up-to-date: 23 May 2004.

Citation: Schroth RJ, Hitchon CA, Uhanova J, Noreddin AM, Taback SP, Moffatt M, Zacharias JM. Hepatitis B vaccination for patients with chronic renal failure. Cochrane Database of Systematic Reviews 2004, Issue 3. Art. No.: CD003775. DOI: 10.1002/14651858.CD003775.pub2.

Copyright (C) 2009 The Cochrane Collaboration. Published by John Wiley \& Sons, Ltd.

\section{A B S T R A C T}

\section{Background}

Chronic renal failure patients are at particular risk of hepatitis B virus infection. Early studies have demonstrated that renal failure patients benefit from vaccination; however, not all studies have consistently shown benefit.

\section{Objectives}

To determine the beneficial and harmful effects of hepatitis B vaccine and of a reinforced vaccination series in chronic renal failure patients.

\section{Search methods}

We searched The Cochrane Hepato-Biliary Group Controlled Trials Register, The Cochrane Renal Group Controlled Trials Register, The Cochrane Controlled Trials Register on The Cochrane Library (Issue 1, 2002), PubMed/MEDLINE (1966 to July 2003), EMBASE (1985 to November 2003), Current Clinical Practice Guidelines (Canadian Immunization Guide and Vaccine Preventable Diseases Surveillance Manual), and Science Citation Index as well as journals, published abstracts, and reference lists of articles.

\section{Selection criteria}

Randomised clinical trials comparing plasma vaccine with placebo, recombinant vaccine with placebo, recombinant vaccine with plasma vaccine, and a reinforced vaccination series (ie, more than three inoculations) with three inoculations of vaccine in chronic renal failure patients.

\section{Data collection and analysis}

Primary outcome measures included incidence of patients developing hepatitis B virus antibodies and infections while secondary outcomes included adverse events, liver-related morbidity, and mortality. Random effects models were used and reported relative risks and $95 \%$ confidence intervals (RR and 95\% CI). 


\section{Main results}

We included seven randomised clinical trials. None of them had high quality. Plasma vaccine was significantly more effective than placebo in achieving hepatitis B antibodies (RR 23.0, 95\% CI 14.39 to 36.76, 3 trials). We found no statistically significant difference between plasma vaccine or placebo regarding hepatitis B virus infections (RR 0.50, 95\% CI 0.20 to 1.24 ). We found no statistically significant differences between recombinant vaccine and plasma vaccine in achieving hepatitis B antibodies (RR 0.65 , $95 \%$ CI 0.28 to 1.53, 2 trials). Heterogeneity was significant and appeared to be attributable to the dose of vaccine. Two trials examined a reinforced recombinant vaccine strategy, which was not statistically more effective than three inoculations of recombinant vaccine regarding development of hepatitis B antibodies (RR $1.36,95 \%$ CI 0.85 to 2.16 ).

\section{Authors' conclusions}

Plasma derived vaccines are more effective than placebo in achieving hepatitis B antibodies, while no statistically significant difference was found between recombinant and plasma vaccines. No statistically significant difference of effectiveness was observed between a reinforced vaccination series versus routine vaccinations of three inoculations of recombinant vaccine.

\section{PLAIN LANGUAGESUMMARY}

\section{Hepatitis B vaccines achieve antibody production in patients with chronic renal failure, but we do not know if the vaccines are protective}

Patients with chronic renal failure are at increased risk of hepatitis B virus infections. This review was undertaken to determine the beneficial and harmful effects of vaccination against hepatitis B and of a reinforced recombinant vaccination series. None of the trials had high methodological quality. Plasma vaccine was significantly more effective than placebo in achieving hepatitis B antibodies. Yet no statistically significant difference was found between the use of plasma vaccine or placebo in preventing hepatitis B virus infections. No trials comparing recombinant vaccine with placebo were identified. There was no significant difference between recombinant and plasma vaccines or between a reinforced vaccination series and routine vaccinations of three inoculations using recombinant vaccine regarding achieving hepatitis $\mathrm{B}$ antibodies.

\section{B A C K G R O U N D}

Hepatitis B virus (HBV) is one of the most frequent viral infections in humans with estimates of 200 to 500 million infected people worldwide (Specter 1999; Fabrizi 2000). Infection can occur either through perinatal transmission, which is the cause of 35 to 40 per cent of new infections worldwide (Fabrizi 2000) or horizontally through exposure to infected blood or other body fluids. While the perinatal (vertical) mode of transmission is of increasing concern in specific geographic regions (Fabrizi 2000) much more attention has been focused on the horizontal transmission of the HBV among high-risk populations. The high-risk population for horizontal transmission includes health-care workers, chronic renal failure (CRF) patients (Torres 1996; Jefferson 2000), and homosexual men (MacKellar 2001).

CRF patients are at particular risk of $\mathrm{HBV}$ infection due to their increased exposure to blood products, haemodialysis (Crosnier 1981; Desmyter 1983; Jilg 1986a; Seaworth 1988a; Dukes 1993;
El-Reshaid 1994; Jungers 1994a), and an impaired immune response (Revillard 1979; Chatenoud 1986; Chatenoud 1990; Johnson 1992). The impaired immune response affects hepatitis $B$ vaccine efficacy. Cases of infections among renal patients undergoing dialysis are generally mild, but up to 80 per cent may progress into chronic carriers. This poses risk to other haemodialysis recipients in the same clinical facility (Desmyter 1983; Stevens 1984; Huang 1997). Liver-related morbidity including cirrhosis and hepatocellular carcinoma may also develop. Occurrences of chronic hepatitis in the haemodialysed populace have ranged from 3 to 29 per cent (Huang 1997) and the estimated prevalence of HBV infection has previously been reported to be 1.1 to 6.1 per cent in dialysis patients worldwide (Geerlings 1991; Petrosillo 1993; Tokars 1998). Current data from the United States indicate that the prevalence of HBV infections among those receiving maintenance haemodialysis is 0.9 per cent (Tokars 2000) while the prevalence of $\mathrm{HBV}$ infections among dialysis patients in the developing world range from 12 to 21.6 per cent (Fabrizi 2001). 
Transmission of hepatitis B may be prevented through the administration of hepatitis B vaccine to persons at risk. The first hepatitis vaccine was derived from pooled hepatitis B surface antigen positive plasma and was licensed in the United States of America in 1981 (Fabrizi 2000). Today, recombinant vaccines have largely replaced it (Jilg 1986a; El-Reshaid 1994; Zannolli 1997).

Vaccination efficacy of hepatitis B vaccine may be determined by measuring the serum titres of antibody to the hepatitis B surface antigen (HBsAg). Seroconversion can be used as surrogate marker for protection against hepatitis B (Popper 1990). Titres greater than 10 milli international units per millilitre $(\mathrm{mIU} / \mathrm{mL}$, ie, 10 IU/L) or greater than 10 Sample Ratio Units (SRU) are generally considered protective (Popper 1990). While seroconversion is generally a useful surrogate marker, for some populations it may be inadequate thus necessitating the study of both seroconversion and HBV infections. A systematic review of effectiveness of these vaccines in health-care workers (Jefferson 2000) has shown benefits. Early studies have demonstrated that renal-failure patients benefit from vaccination. However, many have incomplete seroconversion with rates ranging from 32 to 80 per cent, and not all studies have consistently shown benefit (Fabrizi 2000). The Advisory Committee on Immunization Practices recommends a fourdose schedule of recombinant Engerix B $(40 \mu \mathrm{g})$ vaccine in renal patients over 20 years of age (Rangel 2000). The current Center for Disease Control (CDC) recommendations for vaccination of renal patients over 20 years of age also specifies a four dose recombinant vaccine schedule of $40 \mu \mathrm{g}$ Engerix B at 0, 1, 2, and 6 months (CDC 2001). Various strategies employed in HBV vaccination in this population include increased doses of vaccine, reinforced vaccination strategies, and different schedules of vaccine administration (Jilg 1986a; Seaworth 1988a; El-Reshaid 1994). Trials which have investigated variations in vaccine dose, dose scheduling, and the use of adjuvants to enhance seroconversion rates have had variable results (Fabrizi 2000). Thus the optimum strategy for immunizing CRF patients is not clear.

We have been unable to identify systematic reviews or meta-analyses on hepatitis B vaccination for CRF patients. This systematic review investigates the effectiveness and safety of hepatitis $B$ vaccination in providing adequate seroconversion in CRF patients and preventing hepatitis $B$ infections.

\section{O B JECT IVES}

- To identify the beneficial and harmful effects of hepatitis B vaccine in CRF patients.

- To identify the beneficial and harmful effects of a reinforced vaccination series (three inoculations plus one or more booster inoculations) against a vaccination series of three inoculations using hepatitis $B$ vaccine.

\section{METHODS}

\section{Criteria for considering studies for this review}

\section{Types of studies}

\section{Inclusion criteria}

- Randomised clinical trials studying the administration of hepatitis $B$ vaccine to CRF patients, with or without dialysis.

- No language, publication date, or publication status restrictions were imposed.

\section{Exclusion criteria}

- Quasi-randomised trials.

\section{Types of participants}

\section{Inclusion criteria}

- Participants of any age with CRF or receiving dialysis (haemodialysis or peritoneal dialysis) were considered. CRF was defined as serum creatinine greater than $200 \mu \mathrm{mol} / \mathrm{L}$ for a period of more than six months or individuals receiving dialysis (haemodialysis or peritoneal dialysis).

- Participants who were seronegative for HBsAg and seronegative for anti-HBsAg antibodies or unsuccessfully vaccinated against $\mathrm{HBV}(<10 \mathrm{SRU},<10 \mathrm{mIU} / \mathrm{mL},<10 \mathrm{IU} / \mathrm{L}$, or equivalent) (Popper 1990; Alexander 1998) prior to vaccine administration were included (See Additional Tables 01 and 02).

\section{Exclusion criteria}

- Renal transplant patients were excluded from this review as these individuals are immunosuppressed and are receiving immunosuppressant agents to prevent rejection of their transplanted organs (Johnson 1992; Lefebure 1993; Huang 1997; Fivush 1998), and they have essentially normal renal function (Feuerhake 1984).

- Participants infected with the HBV or with evidence of potential infection (elevated transaminases) were excluded.

\section{Types of interventions}

\section{Inclusion criteria}

- Trials comparing the beneficial and harmful effects of hepatitis B vaccines with adjuvant or cytokine co-interventions.

- Trials comparing the beneficial and harmful effects of immunoglobulin prophylaxis. This review was limited to studies looking at active immunization.

- Hepatitis B vaccines (plasma or recombinant (yeast) derived) of all types, dose, and regimens versus placebo, control vaccine, or no vaccine.

- Reinforced schedules of vaccine of three inoculations plus one or more booster inoculations versus standard vaccination with three inoculations of vaccine. 


\section{Types of outcome measures}

\section{Primary outcome measures}

- Seroconversion, ie, proportion of patients with adequate anti-HBs response (> 10 IU/L or SRU) (Table 1; Table 2).

- Hepatitis B infections (as measured by hepatitis B core antigen ( $\mathrm{HBcAg}$ ) positivity or persistent $\mathrm{HBs} \mathrm{Ag}$ positivity), both acute and chronic. Acute (primary) HBV infections were defined as seroconversion to $\mathrm{HBsAg}$ positivity or development of IgM anti-HBc. Chronic HBV infections were defined as the persistence of $\mathrm{HBsAg}$ for more than six months or $\mathrm{HBsAg}$ positivity and liver biopsy compatible with a diagnosis or chronic hepatitis B.

\section{Secondary outcome measures \\ - Adverse events of hepatitis B vaccinations were recorded and were categorized as:}

i) Local injection-site adverse events (as defined in included studies).

ii) Systemic adverse events.

- Liver-related morbidity (elevated transaminases, cirrhosis, hepatocellular carcinoma).

- Mortality.

Where outcomes were reported at various intervals during the randomised trials, we analysed the outcomes reported at the longest period following vaccinations.

\section{Search methods for identification of studies}

- We searched The Cochrane Hepato-Biliary Group Controlled Trials Register, The Cochrane Renal Group Controlled Trials Register, and The Cochrane Controlled Trials Register (Cochrane Library Issue 1, 2002) were searched.

- We conducted electronic searches utilizing PubMed/ MEDLINE (1966 to July 2003) and EMBASE (Excerpta Medica Database) (1985 to 2003) databases (see Appendix 1 for the search strategies and MESH terms utilized). Both MESH and non-MESH terms were used.

- We searched Science Citation Index (Web of Science) utilizing search terms similar to those used for the PubMed/ $M E D L I N E$ and EMBASE searches.

- We searched published abstracts and proceedings from key scientific conferences of renal, hepatology, and immunology societies to identify any trials not published in journal format. This included the Journal American Society of Nephrology, Nephrology Dialysis Transplant - European Dialysis Transplant Association, Hepatology, Journal of Hepatology, American Association for the Study of Liver Diseases, and Vaccine from 1980 to 2002.

- We searched current clinical practice guidelines (Canadian Immunization Guide and Vaccine Preventable Diseases Surveillance Manual) for relevant randomised clinical trials.
- We hand searched reference lists from review articles retrieved from PubMed/MEDLINE and reference lists from randomised clinical trials to identify additional trials.

\section{Data collection and analysis}

\section{Application of inclusion criteria}

We conducted this systematic review and reported findings according to the 'Quality of reporting of meta-analysis guidelines' (QUORUM) (Moher 1999; Walker 1999) and according to the recommendations of The Cochrane Collaboration in The Cochrane Reviewers' Handbook (Clarke 2001).

- We assessed titles of research articles retrieved from the electronic database and hand searches to determine which abstracts should be reviewed for possible inclusion as per the reviewers defined eligibility criteria described under 'Types of studies, 'Types of participants', 'Types of interventions', and 'Types of outcome measures'.

- All abstracts were assessed using the eligibility criteria proposed by the reviewers for selecting papers.

- We listed excluded trials with the reasons for exclusion.

- We resolved discrepancies between individual reviewers through consensus.

\section{Data extraction}

We performed data extraction on all randomised clinical trials meeting eligibility criteria and review objectives. To ensure accuracy, a minimum of three reviewers independently extracted data from each trial.

Data extraction included:

(1) Number of participants in each randomised controlled trial and the number enrolled to receive each intervention.

(2) Demographic composition and baseline clinical information for each intervention group. This included, when specified, age, gender, stage of renal disease, dialysis status (haemodialysis, peritoneal dialysis, and average number of years on dialysis), previous vaccination status (previous vaccination attempts, previously unvaccinated, or unknown), previous antigen status before receiving trial intervention ( $\mathrm{HBs} \mathrm{Ag}$ negative, anti-HBsAg negative), and participant withdrawals or dropouts.

(3) Types of interventions employed (plasma vaccine versus placebo, recombinant vaccine versus plasma vaccine, reinforced vaccination series (three inoculations plus one or more booster inoculations)) versus standard vaccination series (three inoculations).

(4) Information relating to the vaccines (or placebo), the trade name, dose, number of doses utilized in the trial, the immunization schedules utilized (in months, with first inoculation $=0$ months), and route of vaccination if indicated.

(5) Information concerning the primary outcomes utilized in each included randomised clinical trial, the type of immunoassay employed, and the time of assessment of outcomes. 
(6) Primary outcomes collected included the definition of seroconversion in each trial (SRU or IU/L) and the number seroconverted in each group, the definition of partial seroconversion, and the number partially seroconverted if given, and the number of active hepatitis B infections in each group (both acute and chronic).

(7) Secondary outcomes collected included the number of adverse events, deaths, and liver-related morbidity.

\section{Methodological quality}

The methodological quality, defined as the confidence that the design and report will restrict bias in the intervention comparison (Moher 1998), was evaluated independently and unblinded by a minimum of two reviewers. According to empirical evidence (Schulz 1995; Jadad 1996; Kjaergard 2001; Jüni 2001), we assessed the methodological quality of all randomised clinical trials meeting the criteria and objectives of this review by using separate components, ie, generation of the allocation sequence, allocation concealment, blinding, follow-up, and use of intention-to-treat analyses. Components were assessed as adequate, unclear, or inadequate:

(1) Generation of the allocation sequence: adequate (computer generated random numbers or similar), or unclear (not described), or inadequate (other methods).

(2) Allocation concealment: adequate (central independent unit, sealed envelopes, or similar), or unclear (not described), or inadequate (open table of random numbers or similar). In the Table of Characteristics of Included Studies A = adequate, B = unclear, C $=$ inadequate.

(3) Blinding: adequate (double blind (blinding of both participants and investigators) and identical placebo tablets or similar), or unclear (not described), or not performed (tablets versus injections, or similar).

(4) Follow-up: adequate (number and reasons for dropouts and withdrawals described), or unclear (if the report gave impression that there had been no dropouts or withdrawals, but this was not specifically stated), or inadequate (number or reasons for dropouts and withdrawals were not described).

\section{Statistical analysis}

We entered data extracted from included randomised controlled trials into Review Manager 4.2.6. software for statistical analysis. The random effects model was used. Data synthesis was carried out as follows:

- Relative risk and $95 \%$ confidence intervals were computed.

- Chi-squared testing for heterogeneity was performed. A P value of 0.1 was selected (Engels 2000).

- Homogeneity of interventions, participants, and outcomes was assessed prior to combining extracted data from different included randomised clinical trials being compared.

- Variability among trial results was expected, and possibilities included dose, route, frequency, and timing of vaccine administration, along with the populations reported, and the length of follow-up.

- Significant heterogeneity encountered required explanation by the reviewers.

- The reviewers exercised caution when facing the dilemma of low methodological quality for a significant number of included trials. - The results were analysed with intention-to-treat analyses to study beneficial effects.

- Where comparisons involved a small number of included trials, caution was exercised when interpreting meta-analyses..

- 'Subgroup analysis' was performed in cases where comparisons between interventions being considered demonstrated significant heterogeneity.

\section{R E S U L T S}

\section{Description of studies}

See: Characteristics of included studies; Characteristics of excluded studies.

Following the PubMed electronic database search using the search strategy (Appendix 1), we conducted a title search on 954 listed citations, of which 171 abstracts were reviewed. We retrieved one hundred eight full text journal articles including both trials ( $\mathrm{n}=$ $75)$ and review articles $(n=33)$. Only 12 articles were randomised clinical trials that met the criteria for this review. These articles described a total of seven randomised trials.

We conducted a subsequent modified search strategy to detect randomised clinical trials in PubMed, which resulted in 23 unique trials. We then reviewed titles and abstracts of these and obtained five full text articles. However, none met the inclusion criteria. We searched reference lists of identified journal articles but did not identify any additional trials meeting our inclusion criteria. An electronic search of EMBASE retrieved 772 titles, of which 102 abstracts were reviewed. Eighty-six full articles were reviewed; however, none met our inclusion criteria.

The Web of Science electronic search (Science Citation Index) produced 10 titles of which four abstracts were reviewed. No unique randomised trials were found.

Thus we excluded a total of seven randomised clinical trials from this review while another seven met the specified objectives and inclusion criteria. Three trials investigated plasma vaccines versus placebo (Crosnier 1981; Desmyter 1983; Stevens 1984). Two trials investigated the comparison of recombinant and plasma vaccines (Jungers 1994a; Seaworth 1988a). Another two trials compared a reinforced schedule of recombinant vaccine with a vaccination series of three inoculations of recombinant vaccine (El-Reshaid 1994; Jilg 1986a) (See Table of Characteristics of Included Studies).

\section{Plasma derived hepatitis $B$ vaccine versus placebo}

Crosnier 1981

This randomised, double-blinded, placebo-controlled trial reported the use of plasma vaccine (Institut Pasteur Production Vac- 
cine) $5 \mu \mathrm{g}$ versus placebo, both administered at 0,1 , and 2 months. Participants were haemodialysis patients. Outcomes included seroconversion, HBV infections, and adverse events at 12 months. Desmyter 1983

This randomised, double-blinded, and placebo-controlled investigated heat-inactivated (CLB) plasma vaccine $3 \mu \mathrm{g}$ versus placebo for haemodialysis recipients. Inoculations were performed at 0,1 , 2 , and 4 months. Outcomes included seroconversion, partial seroconversion, HBV infections, and adverse events at approximately 14 months.

Stevens 1984

This randomised trial of haemodialysis patients involved the comparison of Heptavax B vaccine $40 \mu \mathrm{g}$ at 0,1 , and 6 months against placebo. Outcomes reported included seroconversions and HBV infections at 24 months.

\section{Recombinant vaccine versus plasma vaccine} Jungers 1994

This randomised trial involved chronic uremic patients. GenHevac B (recombinant) vaccine $20 \mu \mathrm{g}$ with inoculations occurring at $0,1,2,4$, and 12 months was compared with Hevac B (plasma) vaccine $5 \mu \mathrm{g}$ at $0,1,2,4$, and 12 months. Outcomes included both seroconversions and partial seroconversions at 12 months.

Seaworth 1988a

This randomised trial involved CRF patients. This trial compared recombinant and plasma vaccines. Recombivax vaccine $20 \mu \mathrm{g}$ administered at 0,1 , and 6 months was compared with Heptavax B (plasma) vaccine $40 \mu \mathrm{g}$ at $0,1,6$ months. Another comparison involved Recombivax $40 \mu \mathrm{g}$ at $0,1,6$ months against Heptavax B $40 \mu \mathrm{g}$ at 0,1 , and 6 months. We divided the data of the plasma vaccine arm in half in order to undertake the statistical comparisons. Both seroconversions and partial seroconversions at 12 months were reported.

Reinforced vaccination series versus three inoculation vaccination series

El-Reshaid 1994

This was a randomised, single-blinded trial assessing a reinforced vaccination series (three inoculations plus one or more booster inoculations) against a vaccination series of three inoculations using recombinant hepatitis B vaccine. Participants were on either peritoneal dialysis or haemodialysis. Engerix B $40 \mu \mathrm{g}$ was administered at 0,1 , and 6 months for one arm, while another arm received Engerix B $40 \mu \mathrm{g}$ at $0,1,2$, and 6 months. This study also involved an arm of participants receiving Engerix B $20 \mu \mathrm{g}$ at 0, 1, 2, and 6 months but this arm was excluded for the purposes of this review. Outcomes assessed included seroconversion at 24 months.

Jilg 1986a

This study was randomised and involved dialysis patients. Three intervention groups were employed, assessing a primary vaccination series of three inoculations against two reinforced vaccination campaigns utilizing a booster inoculation. Merck Sharp Dohme recombinant vaccine $40 \mu \mathrm{g}$ at 0,1 , and 6 months was compared to the same vaccine dose using the schedule $0,1,2,3,4$, and
5 months and to Merck Sharp Dohme recombinant vaccine 20 $\mu \mathrm{g}$ at $0,1,2,3,4$, and 5 months. We divided the data of the three inoculations arm in half in order to undertake the statistical comparisons. Outcomes reported included seroconversions at 10 months.

\section{Risk of bias in included studies}

The methodological quality of the included trials is described in Table 3. Of the seven trials, none reported on the generation of the allocation sequence, although the Desmyter 1983 trial described a code used for the generation of the allocation sequence. However, this information was found to be insufficient to determine the appropriateness of the generation of the allocation sequence. The allocation concealment was unclear in six trials, but one (Desmyter 1983) was found to have adequate allocation concealment. Three trials were double blinded and used placebo (Crosnier 1981; Desmyter 1983; Stevens 1984), and the remaining four were conducted without blinding. In five trials the number and reason for dropouts and withdrawals were either described (Desmyter 1983; Seaworth 1988a; Stevens 1984) or mentioned (Crosnier 1981; Jungers 1994a). The El-Reshaid 1994 trial had given the number of dropouts and withdrawals but did not provide explanations for these occurrences, while the Jilg 1986a trial completely failed to discuss participant withdrawals or dropouts. The assessed methodological quality of the Jilg 1986a and ElReshaid 1994 studies was very low and the assessed methodological quality of Jungers 1994 a and Seaworth 1988a was equivalent, with both receiving modest scores. Accordingly, none of the trials was of high methodological quality, ie, having adequate generation of the allocation sequence, allocation concealment, blinding, and followup. However, as the important study outcomes were well-defined serologic responses and $\mathrm{HBV}$ infections, inadequate blinding may be of less concern.

\section{Effects of interventions}

\section{Plasma derived hepatitis $B$ vaccine versus placebo}

Rate of seroconversion

Three randomised clinical trials analysed the effectiveness of plasma derived vaccine versus placebo with 933 persons receiving plasma vaccine and 917 receiving placebo vaccination (Crosnier 1981; Desmyter 1983; Stevens 1984). Vaccination with plasma derived vaccine was found to be statistically more effective than placebo in achieving seroconversion and yielded a RR 23.00, 95\% CI 14.39 to 36.76 (Comparison 01-01). The results were homogeneous (chi square $=0.36, \mathrm{df}=2, \mathrm{P}=0.83$ ).

Only one trial provided sufficient information on partial seroconversions (Desmyter 1983) and indicated that partial seroconversions were greater among those in the plasma vaccine group ( $R R$ 
21.52, 95\% CI 10.89 to $42.53, \mathrm{P}<0.00001$ (Comparison 01$02)$ ).

Hepatitis B infections

The use of plasma derived hepatitis B vaccine did not differ significantly from placebo in preventing active $\mathrm{HBV}$ infections and yielded a RR 0.50, CI 0.20 to 1.24 (Comparison 01-03) although a trend was seen in the direction of protection, with two studies showing benefit (Crosnier 1981; Desmyter 1983). However, the analysis also revealed significant heterogeneity (chi squared value of $12.29, \mathrm{df}=2, \mathrm{P}=0.0021)$. Sensitivity analyses were performed on the data from the three trials to identify a possible source of the heterogeneity. One of the trials had a significantly larger population of persons, utilized larger dosages of vaccine, and assessed hepatitis outcomes at two years (Stevens 1984) while the other two trials conducted assessments at 12 and 14 months (Crosnier 1981; Desmyter 1983). The source of plasma vaccines also differed between the studies.

Adverse events and deaths

Two trials reported adverse events and deaths (Crosnier 1981; Desmyter 1983). The use of plasma vaccine appeared to be well tolerated with no significant increase in deaths or adverse events. Both the group receiving plasma vaccine and the group receiving placebo reported a large number of adverse events presumed to be unrelated to the use of hepatitis B vaccine (Desmyter 1983) .

\section{Recombinant versus plasma derived hepatitis $B$ vaccine}

Rate of seroconversion

Two randomised trials comparing recombinant versus plasma derived hepatitis $\mathrm{B}$ vaccines met the inclusion criteria (Seaworth 1988a; Jungers 1994a). A total of 101 participants were inoculated with recombinant derived hepatitis $B$ vaccine and 80 with plasma derived vaccine. One study (Seaworth 1988a) involved two separate comparisons of recombinant vaccine, of differing dosages, to plasma vaccine. For the purposes of this review, we treated these two comparisons as separate studies and therefore we differentiated them by Seaworth 1988a and Seaworth 1988b. We halved the control group data. Although the use of recombinant vaccine was less effective in producing seroconversions than plasma derived vaccine, the difference was not significant (RR 0.65, 95\% CI 0.28 to 1.53 (Comparison 02-01). Heterogeneity was significant (chi square $=10.22, \mathrm{df}=2, \mathrm{P}=0.006$ ).

We conducted sensitivity analyses to determine possible origins of the heterogeneity. Combining the two recombinant groups in Seaworth 1988a together to compare vaccine effectiveness, regardless of the dose of recombinant vaccine used, still tended to favour the use of plasma vaccine, although this was not significant (RR $0.75,95 \%$ CI 0.29 to 1.92 (Comparison 02-03)). Heterogeneity also remained high (chi square $=9.02, \mathrm{df}=2, \mathrm{P}=0.0027$ ). When only the high dose of recombinant vaccine arm in Seaworth 1988a was used to compare plasma and recombinant vaccines, heterogeneity was eliminated (chi square $=2.61, \mathrm{df}=1, \mathrm{P}=0.11)$ and yielded a RR 0.96, 95\% CI 0.58 to 1.57 (Comparison 02-04). Comparison of partial and full seroconversions did not favour the use of recombinant derived vaccine over plasma vaccine and yielded a RR value of $0.97,95 \%$ CI 0.69 to 1.38 (Comparison 02-02). This comparison also demonstrated homogeneity among the studies (chi square $=3.88, \mathrm{df}=2, \mathrm{P}=0.14$ ).

Hepatitis B infections

There was insufficient information reported in the studies of Seaworth 1988a and Jungers 1994 a to assess whether recombinant vaccines differed from plasma derived vaccines in preventing hepatitis B infections.

Adverse events and deaths

There was insufficient information reported in the studies of Seaworth 1988a and Jungers 1994 a to assess deaths and adverse events from receiving recombinant or plasma vaccines.

Reinforced recombinant vaccination series versus three recombinant vaccine inoculations

Rate of seroconversion

Two randomised trials compared the effectiveness of a reinforced vaccination series with three inoculations of recombinant hepatitis B vaccine (Jilg 1986a; El-Reshaid 1994). In total 63 participants received a reinforced series of recombinant vaccine while 43 received three inoculations. One study (Jilg 1986a) involved two separate comparisons of three inoculations of $40 \mu \mathrm{g}$ to six inoculations of $20 \mu \mathrm{g}$ and six inoculations of $40 \mu \mathrm{g}$ to three inoculations of $40 \mu \mathrm{g}$. These two separate comparisons within the same study were differentiated by the use of an asterisk (Jilg 1986a; Jilg 1986b). We halved the control group data. The initial analysis yielded a RR 1.36, $95 \%$ CI 0.85 to 2.16 (Comparison 03-01) and indicated that the reinforced series was not significantly more effective in achieving seroconversions than three inoculations. However, only 106 patients were studied and the possibility of a type II error cannot be excluded. Heterogeneity was insignificant (chi square $=$ 2.59, $\mathrm{df}=2, \mathrm{P}=0.27$ ).

Hepatitis B infections

Insufficient data existed to assess whether a reinforced vaccination series was superior to a series of three inoculations of recombinant hepatitis $B$ vaccine in preventing hepatitis B infections.

Adverse events and death

There was insufficient information reported in these two trials (Jilg 1986a; El-Reshaid 1994) to assess deaths and adverse events.

\section{I S C USSION}

This is the first systematic review of the effectiveness of hepatitis $B$ vaccinations in CRF patients. Seroconversion following hepatitis $B$ vaccination can be used as surrogate marker for protection against hepatitis B (Popper 1990). The results of this review indicate that the use of plasma derived vaccine is effective in achieving seroconversion. However, reductions in HBV infections could not be demonstrated in this population given the wide confdence intervals, the heterogeneity, and the non-significant overall effect. Plasma vaccine is significantly more effective than placebo 
in achieving seroconversion. Recombinant vaccine may be as effective as plasma vaccine in achieving seroconversion. A significant benefit to the use of a reinforced recombinant vaccination series in patients with CRF over the use of three inoculations could not be proven.

Despite a thorough search of the literature we found only seven randomised trials matching the inclusion criteria selected for this review. Although the search for relevant literature was extensive, publication bias cannot be disregarded, as trials with negative results may have been less likely to be published. While the relatively small number of included trials is a limitation of this review, the comparisons between the use of plasma vaccine and placebo involved a large number of participants $(\mathrm{n}=1850)$ (Crosnier 1981; Stevens 1984). The included trials may not have been designed with sufficient power to detect statistically significant differences between HBV infections in the plasma and placebo groups as infection rates were low in some of the studies (Stevens 1984). As infections occurred in those who had previously seroconverted, seroconversion may not be universally protective in renal failure patients (Stevens 1984). In addition, the mean period of haemodialysis did differ between Crosnier 1981 and Stevens 1984, as participants in the Stevens 1984 trial had been receiving haemodialysis for a longer duration than those in the other trial (vaccine groups $9.9 \pm 13.1$ months (Crosnier 1981) and 2.1 \pm 2.1 years (Stevens 1984), placebo groups $6.9 \pm 8.6$ months (Crosnier 1981) and 2.0 \pm 2.3 years (Stevens 1984)) .

Two randomised trials compared recombinant derived vaccine with plasma derived vaccine (Jungers 1994a; Seaworth 1988a). Both of these trials were deemed to be of the same, but low methodological quality and both had inadequate allocation concealment. These two trials had far fewer participants than the trials comparing plasma vaccine with placebo. One of the two studies involved the use of two different doses of Recombivax vaccine ( $20 \mu \mathrm{g}$ and 40 $\mu \mathrm{g}$ ) (Seaworth 1988a). For the purpose of this analysis the plasma arm from this study was used in two different comparisons, which might have introduced bias into the final analysis, although the number of participants was halved. There was significant heterogeneity between the two studies in this comparison. These two limitations preclude the formulation of conclusions based upon the analyses, even though it suggested that there was minimal difference experienced between using recombinant or plasma hepatitis $B$ vaccines.

Only two trials compared the use of a reinforced series against three inoculations of recombinant hepatitis $\mathrm{B}$ vaccine (El-Reshaid 1994; Jilg 1986a). Sample sizes from both studies were very small $(\mathrm{n}=106)$. The methodological quality for these two trials was also deemed to be poor with both having inadequate allocation concealment. The use of two differing doses of vaccine $(20 \mu \mathrm{g}$ and $40 \mu \mathrm{g}$ ) in a reinforced vaccination series (Jilg 1986a) may have affected the outcome. Bias may have also been generated as the arm of three inoculations of $40 \mu \mathrm{g}$ in one trial was involved in two comparisons, although the number of participants was halved. No heterogeneity was exhibited in this analysis. With these limitations, no benefit was found in using a reinforced vaccination series in the CRF population.

Only three of seven included trials were double blinded (Crosnier 1981; Desmyter 1983; Stevens 1984), all of which assessed the use of plasma derived hepatitis B vaccine against placebo. The remaining trials were not blinded. Although non-blinded observers can introduce significant yet unintentional bias into the analysis, the important study outcomes of well-defined serologic responses and HBV infections indicate that inadequate blinding may be of less concern than issues relating to allocation. None of the studies clearly described the generation of the allocation sequence. In addition, allocation concealment was found to be inadequate for all of the studies with the exception of one (Desmyter 1983). This, ultimately limits the interpretability of the analyses undertaken in this review.

While this review found that the use of plasma derived hepatitis B vaccines produced seroconversions that did not differ significantly from recombinant derived vaccines, the current use of plasma vaccines is controversial. Plasma derived vaccines are human blood products and theoretically have the potential for producing adverse effects including blood borne infections. One study (Stevens 1984) observed 101 cases of non-A, non-B hepatitis, which was likely hepatitis $\mathrm{C}$, occurring in both the plasma vaccine and placebo cohorts.

Current practice in North American and European dialysis centres is to use a reinforced vaccination series of four inoculations of Engerix B $(40 \mu \mathrm{g})$ vaccine for those over 20 years of age (Rangel 2000; CDC 2001). The results of this review do not support this practice. However, the limited number of randomised trials, the low methodological quality of assessed trials, and the relatively low number of participants in these trials are obvious limitations hindering the formulation of clear conclusions.

The ideal dosing schedule is uncertain. The current review does not support the administration of more than three doses of vaccine. However, as previously discussed, there are concerns with the quality of this finding. Given the knowledge that CRF patients on haemodialysis have impaired immune response mechanisms (Girndt 2002), it is prudent to determine the adequacy of vaccination in each patient following the third inoculation so that supplemental inoculations can be administered if needed. Further randomised clinical trials of good methodological quality are needed to resolve this issue. Additional factors that need to be considered in determining the effectiveness of hepatitis $B$ vaccination in this population include the dosage of vaccine, the route of administration, and the use of adjuvants.

AUTHORS' CONCLUSIONS 


\section{Implications for practice}

Plasma derived hepatitis B vaccines are clearly more effective at achieving anti-HBs antibodies than placebo. No statistically significant difference was found between the use of recombinant or plasma vaccine. However, given the theoretical potential for transmission of blood born pathogens with plasma derived vaccines, recombinant vaccines remain the vaccine of choice in high-income nations. Overall, hepatitis B vaccines, both plasma derived and recombinant yeast derived, are effective in achieving seroconversions, although two of the three studies of plasma vaccine showed short term benefits in preventing HBV infections. This review did not show that either vaccine prevents HBV infections in chronic renal failure patients.

No statistically significant difference of effectiveness was observed between reinforced vaccination series and routine vaccinations of three inoculations using recombinant derived vaccine.

There is still insufficient information on adverse effects among chronic renal failure patients but the data reviewed do not indicate that vaccinations cause harm.

\section{Implications for research}

Determining the most effective method of achieving seroconversion and preventing hepatitis $\mathrm{B}$ infections in the chronic renal failure population using recombinant vaccines is needed since this question has not been answered by currently available randomised clinical trials. Future randomised clinical trials with large sample sizes are encouraged to compare plasma derived vaccines with recombinant vaccines among persons with impaired immunity.

Further randomised clinical trials of high methodological quality addressing a reinforced vaccination series (three inoculations plus one or more booster inoculations) of recombinant hepatitis $B$ vaccines against a vaccination series of three inoculations plus placebo booster inoculations would be of benefit to determine the most optimal schedule for attaining seroconversion. To date there are insufficient randomised trials on which to formulate clinical practice recommendations. Future directions in enhancing hepatitis $B$ vaccine effectiveness in chronic renal failure patients may involve the use of adjuvants. As this review did not assess route of administration, or compare differing doses of vaccines, these issues require future investigation. Future trials ought to adopt the CONSORT Guidelines (Consolidated Standards of Reporting Trials) (CONSORT Statement) in their reporting.

\section{ACKNOW LEDGEMENTS}

The reviewers would like to thank the following people: Ms. Ellen Crumley, Centres for Health Evidence Demonstration Project; Mr. B. Poluha and Mr. M. Tennenhouse, Neil John McLean Library, University of Manitoba.

\section{R E F E R E N C E S}

\section{References to studies included in this review}

Crosnier 1981 \{published data only\}

Crosnier J. Hepatitis B in haemodialysis: vaccination against HBs antigen. Proceedings of the European Dialysis and Transplantation Association. European Dialysis and Transplant Association. 1981; Vol. 18:231-40.

* Crosnier J, Jungers P, Courouce AM, Laplanche A, Benhamou E, Degos F, et al.Randomised placebo-controlled trial of hepatitis $B$ surface antigen vaccine in french haemodialysis units: II, Haemodialysis patients. Lancet 1981;1(8224):797-800.

Degos F, Courouce AM, Vitviski L, Lacour B, Crosnier J. Incidence of hepatitis during a placebo controlled study of vaccine against hepatitis B virus. Liver 1982;3 Pt 2(2):317.

Desmyter 1983 \{published data only\}

Desmyter J, Colaert J, De Groote G, Reynders M, ReerinkBrongers EE, Leli PN, et al.Efficacy of heat-inactivated hepatitis B vaccine in haemodialysis patients and staff. Double-blind placebo-controlled trial. Lancet 1983;2 (8363):1323-8.

El-Reshaid 1994 \{published data only\} El-Reshaid K, Al-Mufti S, Johny KV, Sugathan TN.
Comparison of two immunization schedules with recombinant hepatitis $B$ vaccine and natural immunity acquired by hepatitis $\mathrm{B}$ infection in dialysis patients. Vaccine 1994;12(3):223-38.

Jilg 1986a \{published data only\}

Jilg W, Schmidt M, Weinel B, Kuttler T, Brass H, Bommer J, et al.Immunogenicity of recombinant hepatitis $B$ vaccine in dialysis patients. Journal of Hepatology 1986;3(2):190-5.

\section{Jilg 1986b \{published data only\}}

Jilg W, Schmidt M, Weinel B, Kuttler T, Brass H, Bommer $\mathrm{J}$, et al.Immunogenicity of recombinant hepatitis $\mathrm{B}$ vaccine in dialysis patients. Journal of Hepatology 1986;3(2):190-5.

Jungers 1994a \{published data only\} Jungers P, Chauveau P, Courouce AM, Abbassi A, Devillier $\mathrm{P}$, Marie FN, et al.[Recombinant vaccine and extracting vaccine against hepatitis $B$ in patients with kidney insufficiency: comparative immunogenicity]. La Presse Medicale 1994;23(6):277-80.

Jungers P, Chauveau P, Courouce AM, Devillier P, Excler JL, Bailleux F, et al.Immunogenicity of the recombinant GenHevac B Pasteur vaccine against hepatitis B in chronic uremic patients. The Journal of Infectious Diseases 1994;169 (2):399-402. 
Seaworth 1988a \{published data only\}

* Seaworth B, Drucker J, Starling J, Drucker R, Stevens C, Hamilton J. Hepatitis B vaccine in patients with chronic renal failure before dialysis. The Journal of Infectious Diseases 1988;157(2):332-7.

Seaworth 1988b \{published data only\}

* Seaworth B, Drucker J, Starling J, Drucker R, Stevens C, Hamilton J. Hepatitis B vaccine in patients with chronic renal failure before dialysis. The Journal of infectious diseases 1988;157(2):332-7.

Stevens 1984 \{published data only\}

Stevens CE, Alter HJ, Taylor PE, Zang EA, Harley EJ, Szmuness W. Hepatitis B vaccine in patients receiving hemodialysis. Immunogenicity and efficacy. The New England Journal of Medicine 1984;311(8):496-501.

\section{References to studies excluded from this review}

\section{Andre 1987 \{published data only\}}

Andre FE, Safary A. Summary of clinical findings on Engerix-B, a genetically engineered yeast derived hepatitis B vaccine. Postgraduate Medical Journal 1987;63 Suppl2: $169-77$.

\section{Chang 1996 \{published data only\}}

Chang PC, Schrander-van der Meer AM, van Dorp WT, van Leer E. Intracutaneous versus intramuscular hepatitis $B$ vaccination in primary non-responding haemodialysis patients. Nephrology, dialysis, transplantation: official publication of the European Dialysis and Transplant Association - Eurpoean Renal Association 1996;11(1):191-3.

Charest 2000 \{published data only\}

Charest AF, McDougall J, Goldstein MB. A randomized comparison of intradermal and intramuscular vaccination against hepatitis B virus in incident chronic hemodialysis patients. American journal of kidney diseases: the official journal of the National Kidney Foundation 2000;36(5): 976-82.

Jungers 1994b \{published data only\} Jungers P, Devillier P, Salomon H, Cerisier JE, Courouce AM. Randomised placebo-controlled trial of recombinant interleukin-2 in chronic uraemic patients who are nonresponders to hepatitis B vaccine. Lancet 1994;344(8926): 856-7.

Propst 1998 \{published data only\}

Propst T, Propst A, Lhotta K, Vogel W, Konig P. Reinforced intradermal hepatitis $\mathrm{B}$ vaccination in hemodialysis patients is superior in antibody response to intramuscular or subcutaneous vaccination. American Journal of Kidney Diseases: the Official Journal of the National Kidney Foundation 1998;32(6):1041-5.

Vincent 1998 \{published data only\}

Vincent L, John GT, Abraham P, Jacob CK. An intradermal vaccine protocol against hepatitis $B$ in a haemodialysis population. The National Medical Journal of India 1998;11 (1):48.
Vlassopoulos 1999 \{published data only\}

Vlassopoulos DA, Arvanitis DK, Lilis DS, Louizou KI, Hadjiconstantinou VE. Lower long-term efficiency of intradermal hepatitis B vaccine compared to the intramuscular route in hemodialysis patients. The International Journal of Artificial Organs 1999;22(11): 739-43.

\section{Additional references}

\section{Alexander 1998}

Alexander D, Peacock E, Curry G, Jacob G. Immunizing the ESRD patient population: providers face challenges. Nephrology News \& Issues 1998;12(10):42-4;45-6;66.

\section{CDC 2001}

Center for Disease Control. Recommendations for preventing transmission of infections among chronic hemodialysis patients. MMWR. Recommendations and Reports: Morbidity and Mortality Weekly Report: Recommendations and Reports/Centers for Disease Control. Vol. 50 (RR-5), Altanta, Georgia: CDC, 2001:1-43.

\section{Chatenoud 1986}

Chatenoud L, Dugas B, Beaurain G, Touam M, Drueke $\mathrm{T}$, Vasquez A, et al.Presence of preactivated $\mathrm{T}$ cells in hemodialyzed patients: their possible role in altered immunity. Proceedings of the National Academy of Sciences of the United States of America 1986;83(19):7457-61. [MEDLINE: PMID: 3094009]

\section{Chatenoud 1990}

Chatenoud L, Herbelin A, Beaurain G, Descamps-Latscha B. Immune deficiency of the uremic patient. Advances in nephrology from the Necker Hospital 1990;19:259-74. [MEDLINE: PMID: 2105582]

Clarke 2001

Clarke M, Oxman AD, editors. Cochrane Reviewers' Handbook 4.1.4 [updated October 2001]. In: The Cochrane Library, Issue 4. 2001. Oxfrod: Update Software. Updated quarterly.

\section{CONSORT Statement}

Moher D, Schulz KF, Altman DG for the CONSORT Group. The CONSORT statement: revised recommendations for improving the quality of reports of parallel group randomized trials. www.consortstatement.org (accessed 21 November 2002).

Dukes 1993

Dukes CS, Street AC, Starling JF, Hamilton JD. Hepatitis $B$ vaccination and booster in predialysis patients: a 4-year analysis. Vaccine 1993;11(12):1229-32.

Engels 2000

Engels EA, Schmid CH, Terrin N, Olkin I, Lau J.

Heterogeneity and statistical significance in meta-analysis: an empirical study of 125 meta-analyses. Statistics in Medicine 2000;19(13):1707-28.

\section{Fabrizi 2000}

Fabrizi F, Martin P. Hepatitis B virus infection in dialysis patients. American Journal of Nephrology 2000;20(1):1-11. 


\section{Fabrizi 2001}

Fabrizi F, Martin P, Lunghi G, Ponticelli C. Novel evidence on hepatitis B virus infection in dialysis. The International Journal of Artificial Organs 2001;24(1):8-16.

Feuerhake 1984

Feuerhake A, Muller R, Lauchart W, Pichlmayr R, Schmidt FW. HBV - vaccination in recipients of kidney allografts. Vaccine 1984;2(4):255-6. [MEDLINE: PMID: 6241770]

\section{Fivush 1998}

Fivush BA, Neu AM. Immunization guidelines for pediatric renal disease. Seminars in Nephrology 1998;18(3):256-63.

\section{Geerlings 1991}

Geerlings W, Tufveson G, Brunner FP, Ehrich JH, Fassbinder W, Landais $\mathrm{P}$, et al.Combined report on regular dialysis and transplantation in Europe, XXI, 1990. Nephrology, Dialysis, Tranpslantation: Official Publication of the European Dialysis and Transplant Association - European Renal Association 1991;6 Suppl4:5-29.

\section{Girndt 2002}

Girndt M, Kohler H. Hepatitis B virus infection in hemodialysis patients. Seminars in Nephrology 2002;22(4): 340-50. [: PMID 12118399]

\section{Huang 1997}

Huang CC. Hepatitis in patients with end-stage renal disease. Journal of Gastroenterology and Hepatology 1997;12 (9-10):S236-41.

\section{Jadad 1996}

Jadad AR, Moore RA, Carroll D, Jenkinson C, Reynolds DJ, Gavaghan DJ, et al.Assessing the quality of reports of randomized clinical trials: is blinding necessary?. Controlled Clinical Trials 1996;17(1):1-12.

\section{Jefferson 2000}

Jefferson T, Demicheli V, Deeks J, MacMillan A, Sassi F, Pratt M. Vaccines for preventing hepatitis B in healthcare workers. Cochrane Library 2000, Issue 1.[Art. No.: CD000100. DOI: 10.1002/14651858.CD000100.pub3]

\section{Johnson 1992}

Johnson DW, Fleming SJ. The use of vaccines in renal failure. Clinical Pharmacokinetics 1992;22(6):434-46.

\section{Jüni 2001}

Jüni P, Altman DG, Egger M. Systematic reviews in health care: Assessing the quality of controlled clinical trials. British Medical Journal 2001;323(7303):42-6.

\section{Kjaergard 2001}

Kjaergard LL, Villumsen J, Gluud C. Reported methodologic quality and discrepancies between large and small randomized trials in meta-analyses. Annals of Internal Medicine 2001;135(11):982-9.

\section{Lefebure 1993}

Lefebure AF. Immunogenicity of a recombinant DNA hepatitis $\mathrm{B}$ vaccine in renal transplant patients. Vaccine 1993;11(4):397-9.

\section{MacKellar 2001}

MacKellar DA, Valleroy LA, Secura GM, McFarland W, Shehan D, Ford W, et al.Two decades after vaccine license: hepatitis B immunization and infection among young men who have sex with men. American Journal of Public Health 2001;91(6):965-71.

\section{Moher 1998}

Moher D, Pham B, Jones A, Cook DJ, Jadad A, Moher $\mathrm{M}$, et al.Does quality of reports of randomised trials affect estimates of intervention efficacy reported in meta-analysis. Lancet 1998;352(9128):609-13.

\section{Moher 1999}

Moher D, Cook DJ, Eastwood S, Olkin I, Rennie D, Stroup DF. Improving the quality of reports of meta-analyses of randomised controlled trials: the QUORUM statement. Lancet 1999;354(9193):1896-900.

\section{Petrosillo 1993}

Petrosillo N, Puro V, Ippolito G. Prevalence of human immunodeficiency virus, hepatitis $B$ virus and hepatitis $C$ virus among dialysis patients. The Italian Multicentric Study on Nosocomial and Occupational Risk of BloodBorne Infections in Dialysis. Nephron 1993;64(4):636-9. [MEDLINE: PMID: 8366992]

\section{Popper 1990}

Popper H, Schaffner F. Progress in liver diseases. Vol. 9, Toronto: W.B. Saunders Company, 1990.

\section{Rangel 2000}

Rangel MC, Coronado VG, Euler GL, Strikas RA. Vaccine recommendations for patients on chronic dialysis. The Advisory Committee on Immunization Practices and the American Academy of Pediatrics. Seminars in Dialysis 2000; 13(2):101-7.

\section{Revillard 1979}

Revillard JP. Immunologic alterations in chronic renal insufficiency. Advances in Nephrology from the Necker Hospital 1979;8:365-82. [MEDLINE: PMID: 115248]

\section{Schulz 1995}

Schulz KF, Chalmers I, Hayes RJ, Altman DG. Empirical evidence of bias. Dimensions of methodological quality associated with estimates of treatment effects in controlled trials. JAMA 1995;273(5):408-12.

\section{Specter 1999}

Specter SC. Hepatitis B vaccines. In: Specter SC editor (s). Viral Hepatitis: Diagnosis, Therapy, and Prevention. Totowa, NJ: Humana Press, 1999:377-91. [: ISBN 0-89603-424-0]

\section{Tokars 1998}

Tokars JI, Miller ER, Alter MJ, Arduino MJ. National surveillance of dialysis associated diseases in the United States, 1995. ASAIO Journal (American Society for Artificial Internal Organs: 1992) 1998;44(1):98-107. [MEDLINE: PMID: 9466509]

\section{Tokars 2000}

Tokars JI, Miller ER, Alter MJ, Arduino MJ. National surveillance of dialysis-associated diseases in the United States, 1997. Seminars in Dialysis 2000;13(2):75-85. 
Torres 1996

Torres JR. Hepatitis B and hepatitis delta virus infection in South America. Gut 1996;38 Suppl 2:S48-55.

Walker 1999

Walker A. Meta-style and expert review. Lancet 1999;354 (9193):1834-5.

Zannolli 1997

Zannolli R, Morgese G. Hepatitis B vaccine: current issues. The Annals of Pharmacotherapy 1997;31(9):1059-67.

* Indicates the major publication for the study 


\section{CHARACTERISTICS OF STUDIES}

\section{Characteristics of included studies [ordered by study ID]}

\section{Crosnier 1981}

\begin{tabular}{|c|c|c|}
\hline Methods & \multicolumn{2}{|c|}{$\begin{array}{l}\text { Randomised clinical trial, double-blind, placebo controlled, withdrawals/dropouts discussed. } \\
43 \text { dropouts. } \\
\text { * For assessment of methodological quality, please see Additional Table } 04\end{array}$} \\
\hline Participants & \multicolumn{2}{|c|}{ Haemodialysis patients. } \\
\hline Interventions & \multicolumn{2}{|c|}{$\begin{array}{l}\text { Institut Pasteur production vaccine (plasma) } 5 \mu \mathrm{g} \text { at } 0,1 \text {, and } 2 \text { months versus placebo at } 0,1 \text {, and } 2 \\
\text { months }\end{array}$} \\
\hline Outcomes & \multicolumn{2}{|c|}{ Anti-HBs seroconversion active hepatitis B infections, and adverse events, deaths at 12 months } \\
\hline Notes & \multicolumn{2}{|c|}{ Plasma vaccine versus placebo. } \\
\hline \multicolumn{3}{|l|}{ Risk of bias } \\
\hline Item & Authors' judgement & Description \\
\hline Allocation concealment? & Unclear & B - Unclear \\
\hline
\end{tabular}

\section{Desmyter 1983}

\begin{tabular}{|c|c|c|}
\hline Methods & \multicolumn{2}{|c|}{$\begin{array}{l}\text { Randomised clinical trial, double-blind, placebo controlled, withdrawals/dropouts discussed. } \\
13 \text { dropouts. } \\
\text { * For assessment of methodological quality, please see Additional Table } 04\end{array}$} \\
\hline Participants & \multicolumn{2}{|c|}{$\begin{array}{l}\text { Haemodialysis patients } \\
\text { (vaccine }=94>1 \text { year, placebo }=80>1 \text { year) }\end{array}$} \\
\hline Interventions & \multicolumn{2}{|c|}{ CLB (plasma) vaccine $3 \mu \mathrm{g}$ at $0,1,2$, and 5 versus placebo at $0,1,2$, and 5 months } \\
\hline Outcomes & \multicolumn{2}{|c|}{$\begin{array}{l}\text { Anti-HBs seroconversion, partial seroconversion, active hepatitis B infections, adverse events, deaths at } \\
14 \text { months }\end{array}$} \\
\hline Notes & \multicolumn{2}{|c|}{ Plasma vaccine versus placebo. } \\
\hline \multicolumn{3}{|l|}{ Risk of bias } \\
\hline Item & Authors' judgement & Description \\
\hline Allocation concealment? & Yes & A - Adequate \\
\hline
\end{tabular}


El-Reshaid 1994

\begin{tabular}{|c|c|c|}
\hline Methods & \multicolumn{2}{|c|}{$\begin{array}{l}\text { Randomised clinical trial, single-blinded, withdrawals/dropouts discussed. } \\
9 \text { dropouts. } \\
\text { * For assessment of methodological quality, please see Additional Table } 04\end{array}$} \\
\hline Participants & \multicolumn{2}{|c|}{ Peritoneal and haemodialysis patients. } \\
\hline Interventions & \multicolumn{2}{|c|}{$\begin{array}{l}\text { Engerix B (recombinant) } 40 \mu \mathrm{g} \text { at } 0,1 \text {, and } 6 \text { versus Engerix B (recombinant) } 40 \mu \mathrm{g} \text { at } 0,1,2 \text {, and } 6 \\
\text { months. } \\
\text { (Also Engerix B (recombinant) } 20 \mu \mathrm{g} \text { at } 0,1 \text {, and } 6 \text { months was assessed, but this arm was excluded for the } \\
\text { purposes of this review as this was for healthy staff and not related to the } 3 \text { inoculation versus reinforced } \\
\text { series debate) }\end{array}$} \\
\hline Outcomes & \multicolumn{2}{|c|}{ Anti-HBs seroconversion, active infections at 24 months. } \\
\hline Notes & \multicolumn{2}{|c|}{ Recombinant vaccine schedule. } \\
\hline \multicolumn{3}{|l|}{ Risk of bias } \\
\hline Item & Authors' judgement & Description \\
\hline Allocation concealment? & Unclear & B - Unclear \\
\hline
\end{tabular}

\section{Jilg 1986a}

\begin{tabular}{|c|c|c|}
\hline Methods & \multicolumn{2}{|c|}{$\begin{array}{l}\text { Randomised clinical trial, not blinded. } \\
\text { * For assessment of methodological quality, please see Additional Table } 04\end{array}$} \\
\hline Participants & \multicolumn{2}{|l|}{ Dialysis patients. } \\
\hline Interventions & \multicolumn{2}{|c|}{$\begin{array}{l}\text { Merck Sharp Dohme (recombinant) } 40 \mu \mathrm{g} \text { at } 0,1,6 \text { versus Merck Sharp Dohme (recombinant) } 40 \mu \mathrm{g} \text { at } \\
0,1,2,3,4 \text {, and } 5 \text { months } \\
\text { Merck Sharp Dohme (recombinant) } 40 \mu \mathrm{g} \text { at } 0,1,6 \text { versus Merck Sharp Dohme (recombinant) } 20 \mu \mathrm{g} \text { at } \\
0,1,2,3,4,5\end{array}$} \\
\hline Outcomes & \multicolumn{2}{|c|}{ Anti-HBs seroconversion at 10 months. } \\
\hline Notes & \multicolumn{2}{|c|}{$\begin{array}{l}\text { Recombinant vaccine schedule (groups } 1 \text { and } 3 \text { combined). } \\
\text { Recombinant vaccine schedule (groups } 1 \text { and } 2 \text { combined). }\end{array}$} \\
\hline \multicolumn{3}{|l|}{ Risk of bias } \\
\hline Item & Authors' judgement & Description \\
\hline Allocation concealment? & Unclear & B - Unclear \\
\hline
\end{tabular}


Jilg 1986b

\begin{tabular}{|c|c|c|}
\hline Methods & \multicolumn{2}{|l|}{ Please see Jilg 1986a } \\
\hline \multicolumn{3}{|l|}{ Participants } \\
\hline \multicolumn{3}{|l|}{ Interventions } \\
\hline \multicolumn{3}{|l|}{ Outcomes } \\
\hline \multicolumn{3}{|l|}{ Notes } \\
\hline \multicolumn{3}{|l|}{ Risk of bias } \\
\hline Item & Authors' judgement & Description \\
\hline Allocation concealment? & Unclear & B - Unclear \\
\hline
\end{tabular}

\section{Jungers 1994a}

\begin{tabular}{|c|c|c|}
\hline Methods & \multicolumn{2}{|c|}{$\begin{array}{l}\text { Randomised clinical trial, withdrawals/dropouts discussed. } \\
16 \text { dropouts. } \\
\text { (Not blinded) } \\
\text { * For assessment of methodological quality, please see Additional Table } 04\end{array}$} \\
\hline Participants & \multicolumn{2}{|c|}{ Chronic uremic patients (not on dialysis). } \\
\hline Interventions & \multicolumn{2}{|c|}{$\begin{array}{l}\text { Hevac B (plasma) vaccine } 5 \mu \mathrm{g} \text { at } 0,1,2,4 \text {, and } 12 \text { months versus GenHevac B (recombinant) vaccine } \\
20 \mu \mathrm{g} \text { at } 0,1,2,4 \text {, and } 12 \text { months }\end{array}$} \\
\hline Outcomes & \multicolumn{2}{|c|}{ Anti-HBs seroconversion, partial seroconversion at 12 months } \\
\hline Notes & \multicolumn{2}{|c|}{ Recombinant versus plasma. } \\
\hline \multicolumn{3}{|l|}{ Risk of bias } \\
\hline Item & Authors' judgement & Description \\
\hline Allocation concealment? & Unclear & B - Unclear \\
\hline
\end{tabular}

Seaworth 1988a

\begin{tabular}{ll}
\hline Methods & $\begin{array}{l}\text { Randomised clinical trial, withdrawals/dropouts, discussed. } \\
8 \text { dropouts. } \\
\text { (Not blinded) } \\
* \text { For assessment of methodological quality, please see Additional Table 04 }\end{array}$ \\
\hline Participants & Chronic renal failure patients (mean $4.5 \mathrm{mg} / \mathrm{dL}$, range 2.0 to 9.8)
\end{tabular}




\section{Seaworth 1988a (Continued)}

\begin{tabular}{|c|c|c|}
\hline Interventions & \multicolumn{2}{|c|}{$\begin{array}{l}\text { Recombivax (recombinant) vaccine } 20 \text { ug at } 0,1,6 \text { months versus recombivax (recombinant) vaccine } 40 \\
\text { ug at } 0,1,6 \text { months versus heptavax } B \text { (plasma) vaccine } 40 \mu \mathrm{g} \text { at } 0,1,6 \text { months }\end{array}$} \\
\hline Outcomes & \multicolumn{2}{|c|}{ Anti-HBs seroconversion, partial seroconversion, deaths at 12 months } \\
\hline Notes & \multicolumn{2}{|c|}{$\begin{array}{l}\text { Recombinant versus plasma (groups } 1 \text { and } 3 \text { combined). } \\
\text { Recombinant versus plasma (groups } 2 \text { and } 3 \text { combined). }\end{array}$} \\
\hline \multicolumn{3}{|l|}{ Risk of bias } \\
\hline Item & Authors' judgement & Description \\
\hline Allocation concealment? & Unclear & B - Unclear \\
\hline
\end{tabular}

Seaworth 1988b

\begin{tabular}{|c|c|c|}
\hline Methods & \multicolumn{2}{|c|}{ Please see Seaworth 1988a } \\
\hline \multicolumn{3}{|l|}{ Participants } \\
\hline \multicolumn{3}{|l|}{ Interventions } \\
\hline \multicolumn{3}{|l|}{ Outcomes } \\
\hline \multicolumn{3}{|l|}{ Notes } \\
\hline \multicolumn{3}{|l|}{ Risk of bias } \\
\hline Item & Authors' judgement & Description \\
\hline Allocation concealment? & Unclear & B - Unclear \\
\hline
\end{tabular}

Stevens 1984

Methods

Randomised clinical trial, double-blind, placebo controlled, withdrawals/dropouts discussed. 98 dropouts.

* For assessment of methodological quality, please see Additional Table 04

\begin{tabular}{ll}
\hline Participants & Haemodialysis patients \\
& $\mathrm{N}=1311$.
\end{tabular}

$\mathrm{N}=1311$.

Interventions Heptavax B (plasma) vaccine $40 \mu \mathrm{g}$ at 0,1 , and 6 months versus placebo at 0,1 , and 6 months

Outcomes Anti-HBs seroconversion, active hepatitis B infections, deaths at 24 months

Notes $\quad$ Plasma versus placebo. 
Stevens 1984 (Continued)

\section{Risk of bias}

\begin{tabular}{|c|c|c|}
\hline Item & Authors' judgement & Description \\
\hline Allocation concealment? & Unclear & B - Unclear \\
\hline
\end{tabular}

Characteristics of excluded studies [ordered by study ID]

\begin{tabular}{|c|c|}
\hline Study & Reason for exclusion \\
\hline Andre 1987 & $\begin{array}{l}\text { A randomised clinical trial of } 6100 \text { people of which } 270 \text { were on chronic haemodialysis (plasma derived vaccine } \\
20 \mu \mathrm{g} \text { at } 0,1 \text {, and } 6 \text { months or } 0,1,2 \text {, and } 12 \text { months versus recombinant vaccine } 2.5 \mu \mathrm{g}, 5 \mu \mathrm{g}, 10 \mu \mathrm{g}, 20 \mu \mathrm{g} \\
\text { at } 0,1 \text {, and } 6 \text { months or } 0,1,2 \text {, and } 12 \text { months). } \\
\text { We were unable to extract data specific to haemodialysis patients from the results presented in this publication }\end{array}$ \\
\hline Chang 1996 & $\begin{array}{l}\text { A randomised clinical trial of recombinant vaccine of different doses, schedules, and routes (HepB-DNA } 40 \mu \mathrm{g} \\
\text { at } 0,1 \text {, and } 3 \text { months intramuscularly versus HepB-DNA } 10 \mu \mathrm{g} \text { at } 0,1,2,3,4,5,6,7,8,9,10 \text {, and } 11 \text { months } \\
\text { intracutaneously). This trial was excluded because it assessed route of vaccine administration }\end{array}$ \\
\hline Charest 2000 & $\begin{array}{l}\text { A randomised clinical trial of recombinant vaccines of different routes, doses, and schedules (Engerix B } 40 \mu \mathrm{g} \\
\text { at } 0,1,2 \text {, and } 6 \text { months intramuscularly versus recombinant hepatitis B vaccine } 5 \mu \mathrm{g} \text { intradermally at } 0 \text { month; } \\
\text { then every two weeks until adequate titres at least } 1000 \mathrm{IU} / \mathrm{L} \text { or until } 2 \text { years). This trial was excluded because } \\
\text { it assessed route of vaccine administration }\end{array}$ \\
\hline Jungers $1994 b$ & $\begin{array}{l}\text { A randomised clinical trial of recombinant vaccine with interleukin- } 2 \text { among non-responders. This trial involved } \\
\text { the use of an adjuvant and was therefore excluded }\end{array}$ \\
\hline Propst 1998 & $\begin{array}{l}\text { A randomised clinical trial of recombinant vaccine of different dose, schedule, and route (Engerix B } 40 \mu \mathrm{g} \\
\mathrm{IM} \text { at } 0,1 \text {, and } 6 \text { months and booster at } 8 \text { and } 12 \text { months if titres less than } 10 \mathrm{IU} / \mathrm{L} \text { versus Engerix B } 20 \mu \mathrm{g} \\
\text { subcutaneously every two weeks up to } 240 \mu \mathrm{g} \text { versus Engerix B } 20 \mu \mathrm{g} \text { intradermally every } 2 \text { weeks up to } 240 \\
\mu \mathrm{g}) \text {. This trial was excluded because it assessed route of vaccine administration }\end{array}$ \\
\hline Vincent 1998 & $\begin{array}{l}\text { A randomised clinical trial of recombinant vaccine of different dose, route and schedule ( } 40 \mu \mathrm{g} \text { intramuscularly } \\
\text { at } 0,4 \text {, and } 8 \text { months versus } 20 \mu \mathrm{g} \text { intradermally at } 0,0.25,0.5,0.75,1 \text {, and } 1.25 \text { months). This trial was } \\
\text { excluded because it assessed route of vaccine administration }\end{array}$ \\
\hline Vlassopoulos 1999 & $\begin{array}{l}\text { A randomised clinical trial of recombinant vaccine of different dose, route and schedule (Engerix, SKB } 5 \mu \mathrm{g} \\
\text { intradermally at } 0,0.5,1,1.5,2,2.5,3 \text {, and } 3.5 \text { months and intramuscular booster at } 12 \text { versus Engerix, SKB } \\
20 \mu \mathrm{g} \text { intramuscularly at } 0,1,2 \text {, and } 12 \text { months). This trial was excluded because it assessed route of vaccine } \\
\text { administration }\end{array}$ \\
\hline
\end{tabular}


DATA AND ANALYSES

Comparison 1. Plasma vaccine versus placebo

\begin{tabular}{|c|c|c|c|c|}
\hline Outcome or subgroup title & $\begin{array}{l}\text { No. of } \\
\text { studies }\end{array}$ & $\begin{array}{c}\text { No. of } \\
\text { participants }\end{array}$ & Statistical method & Effect size \\
\hline 1 Seroconversion to anti-HBs & 3 & 1850 & Risk Ratio (M-H, Random, 95\% CI) & $23.00[14.39,36.76]$ \\
\hline $\begin{array}{l}2 \text { Full and partial anti-HBs } \\
\text { seroconversion }\end{array}$ & 1 & 401 & Risk Ratio (M-H, Random, 95\% CI) & $21.52[10.89,42.52]$ \\
\hline 3 Hepatitis B virus infection & 3 & 1850 & Risk Ratio (M-H, Random, 95\% CI) & $0.50[0.20,1.24]$ \\
\hline 4 Adverse events & 2 & 539 & Risk Ratio (M-H, Random, 95\% CI) & $0.71[0.25,2.05]$ \\
\hline 5 Deaths & 2 & 539 & Risk Ratio (M-H, Random, 95\% CI) & $1.39[0.79,2.44]$ \\
\hline $\begin{array}{l}6 \text { Sensitivity analysis for hepatitis } \\
\text { B virus (HBV) infection } \\
\text { excluding Stevens } 1984\end{array}$ & 2 & 539 & Risk Ratio (M-H, Random, 95\% CI) & $0.33[0.18,0.62]$ \\
\hline
\end{tabular}

Comparison 2. Recombinant vaccine versus plasma vaccine

\begin{tabular}{|c|c|c|c|c|}
\hline Outcome or subgroup title & $\begin{array}{l}\text { No. of } \\
\text { studies }\end{array}$ & $\begin{array}{c}\text { No. of } \\
\text { participants }\end{array}$ & Statistical method & Effect size \\
\hline 1 Anti-HBs seroconversion & 3 & 181 & Risk Ratio (M-H, Random, 95\% CI) & $0.65[0.28,1.53]$ \\
\hline $\begin{array}{l}2 \text { Full and partial seroconversion } \\
\text { to anti-HBs }\end{array}$ & 3 & 181 & Risk Ratio (M-H, Random, 95\% CI) & $0.97[0.69,1.38]$ \\
\hline $\begin{array}{l}3 \text { Sensitivity analysis for anti-HBs } \\
\text { seroconversion - combining } \\
\text { both recombinant arms of } \\
\text { Seaworth } 1988\end{array}$ & 2 & 181 & Risk Ratio (M-H, Random, 95\% CI) & $0.75[0.29,1.92]$ \\
\hline $\begin{array}{l}4 \text { Sensitivity analysis for anti-HBs } \\
\text { seroconversion (excluding the } \\
\text { low dose recombinant arm of } \\
\text { Seaworth 1988) }\end{array}$ & 2 & 160 & Risk Ratio (M-H, Random, 95\% CI) & $0.96[0.58,1.57]$ \\
\hline
\end{tabular}

Comparison 3. Reinforced recombinant vaccination series versus primary recombinant vaccination series

\begin{tabular}{lcccc} 
Outcome or subgroup title & $\begin{array}{c}\text { No. of } \\
\text { studies }\end{array}$ & $\begin{array}{c}\text { No. of } \\
\text { participants }\end{array}$ & Statistical method & Effect size \\
\hline 1 Seroconversion to anti-HBs & 3 & 106 & Risk Ratio (M-H, Random, 95\% CI) & $1.36[0.85,2.16]$ \\
\hline
\end{tabular}




\section{Analysis I.I. Comparison I Plasma vaccine versus placebo, Outcome I Seroconversion to anti-HBs.}

Review: Hepatitis B vaccination for patients with chronic renal failure

Comparison: I Plasma vaccine versus placebo

Outcome: I Seroconversion to anti-HBs

Study or subgroup $\quad$ Plasma vaccine Rlacebo Risk Ratio Ratio H,Random, $95 \% \quad H$, Random $95 \%$

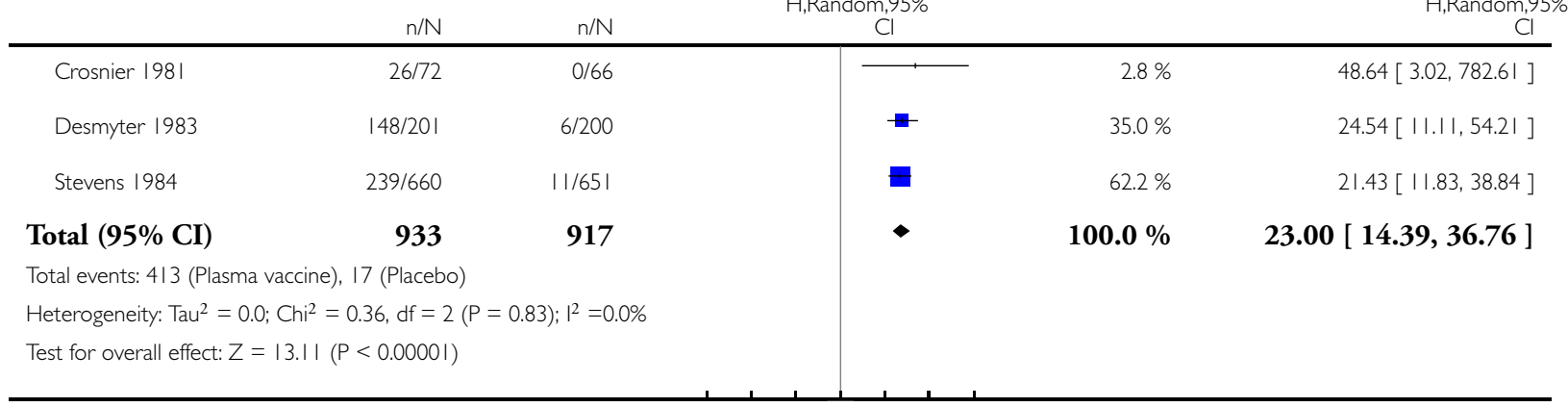

$0.0010 .010 .1 \quad 1 \quad 10 \quad 1001000$

Favours Placebo Favours Plasma

Analysis I.2. Comparison I Plasma vaccine versus placebo, Outcome 2 Full and partial anti-HBs seroconversion.

Review: Hepatitis B vaccination for patients with chronic renal failure

Comparison: I Plasma vaccine versus placebo

Outcome: 2 Full and partial anti-HBs seroconversion

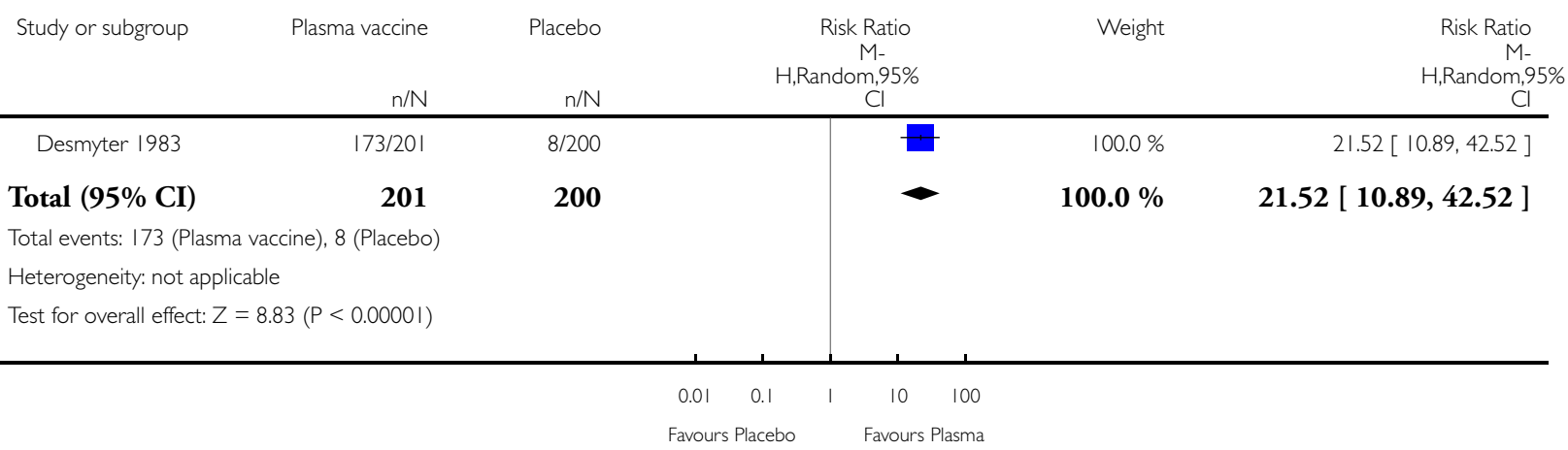




\section{Analysis I.3. Comparison I Plasma vaccine versus placebo, Outcome 3 Hepatitis B virus infection.}

Review: Hepatitis B vaccination for patients with chronic renal failure

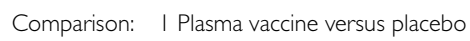

\begin{tabular}{lcr} 
& $n / N$ & $n / N$ \\
\hline Crosnier 1981 & $10 / 72$ & $21 / 66$ \\
Desmyter 1983 & $7 / 201$ & $30 / 200$ \\
Stevens 1984 & $35 / 660$ & $32 / 65$ ।
\end{tabular}

Total (95\% CI)

933

917

Weight

N H,Random, $95 \%$

$\begin{array}{cc} & \begin{array}{c}\text { H,Random,95\% } \\ \text { Cl }\end{array} \\ 32.9 \% & 0.44[0.22,0.86] \\ 30.7 \% & 0.23[0.10,0.52] \\ 36.3 \% & 1.08[0.68,1.72]\end{array}$

Total events: 52 (Plasma vaccine), 83 (Placebo)

Heterogeneity: $\mathrm{Tau}^{2}=0.54 ; \mathrm{Chi}^{2}=12.29, \mathrm{df}=2(\mathrm{P}=0.002) ; \mathrm{I}^{2}=84 \%$

Test for overall effect: $Z=1.49(P=0.14)$

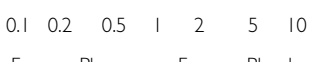

Favours Plasma Favours Placebo

\section{Analysis I.4. Comparison I Plasma vaccine versus placebo, Outcome 4 Adverse events.}

Review: Hepatitis B vaccination for patients with chronic renal failure

Comparison: I Plasma vaccine versus placebo

Outcome: 4 Adverse events

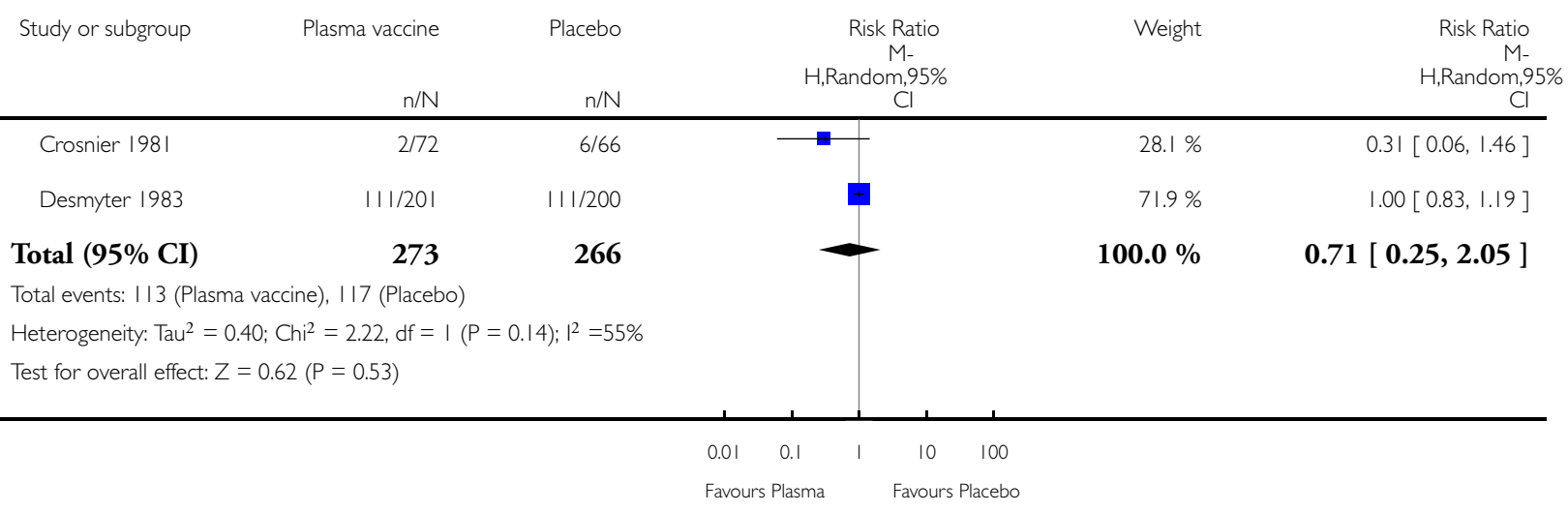

Hepatitis B vaccination for patients with chronic renal failure (Review) 


\section{Analysis I.5. Comparison I Plasma vaccine versus placebo, Outcome 5 Deaths.}

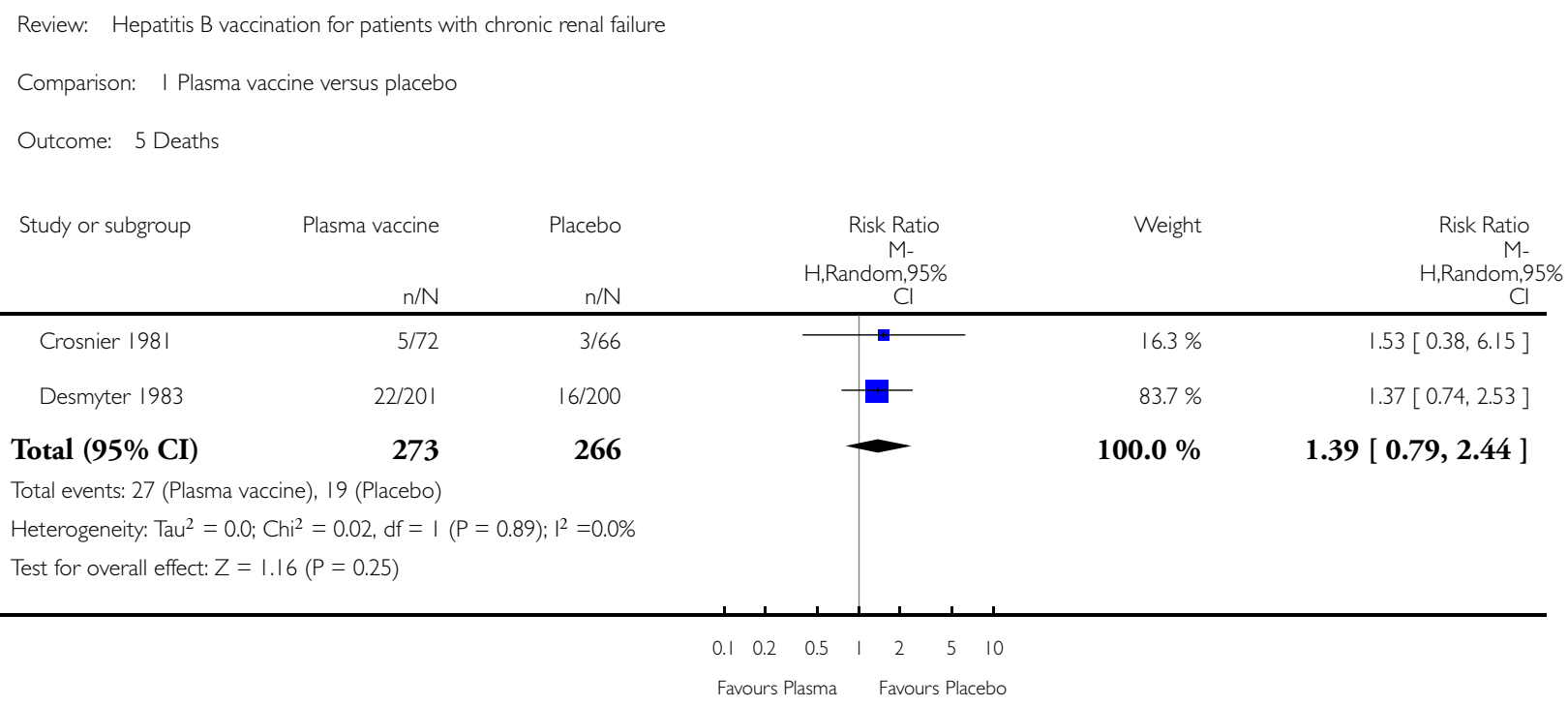


Analysis I.6. Comparison I Plasma vaccine versus placebo, Outcome 6 Sensitivity analysis for hepatitis B virus (HBV) infection excluding Stevens 1984.

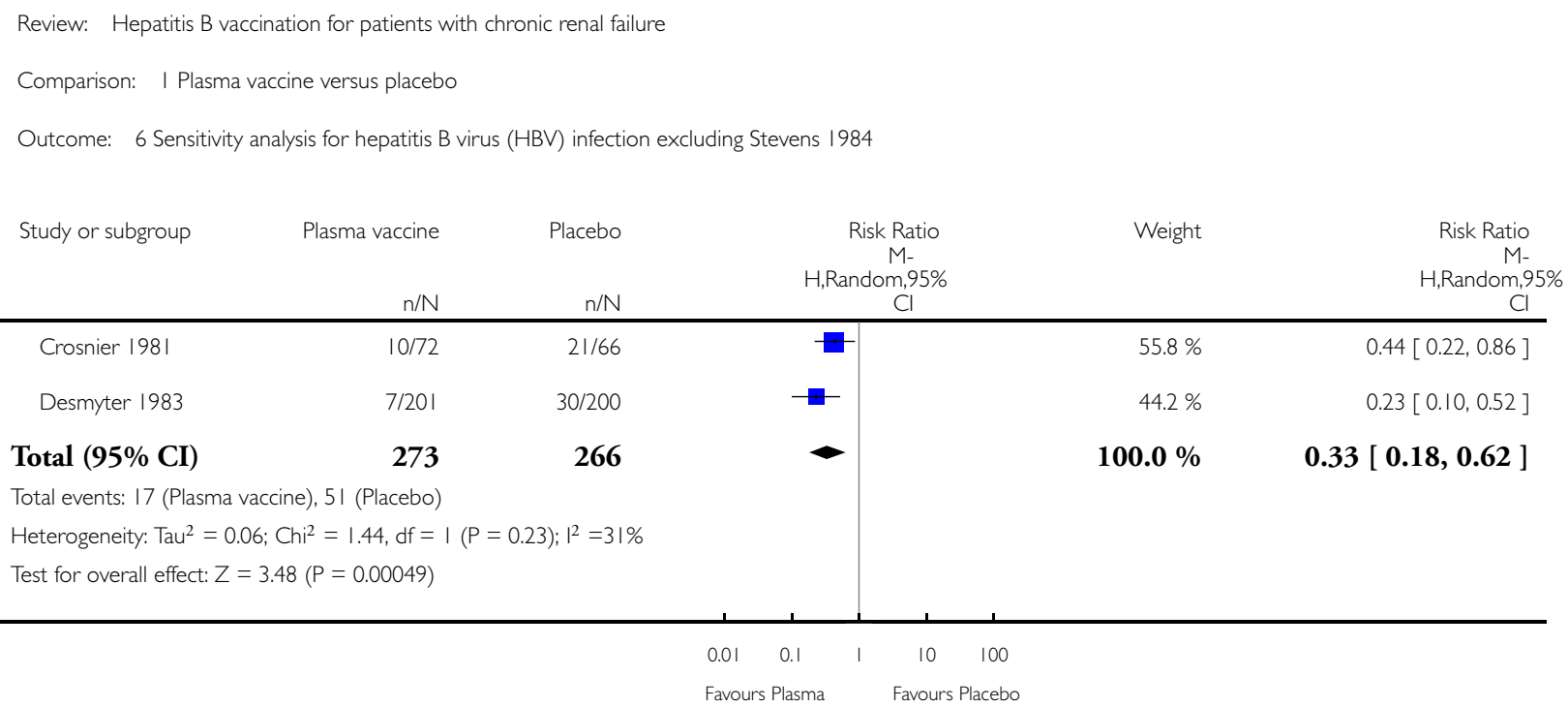

\section{Analysis 2.I. Comparison 2 Recombinant vaccine versus plasma vaccine, Outcome I Anti-HBs} seroconversion.

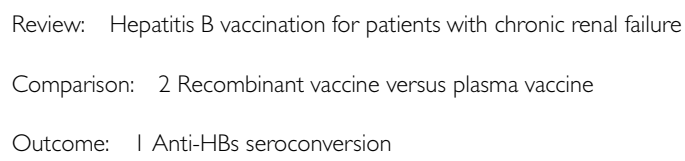

101

$$
7 / 10
$$

80

$\mathrm{N}$

$\mathrm{Cl}$

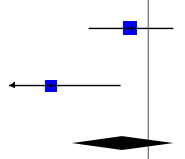

Total events: 55 (Recombinant vaccine), 50 (Plasma vaccine)

Heterogeneity: $\mathrm{Tau}^{2}=0.43 ; \mathrm{Chi}^{2}=10.22, \mathrm{df}=2(\mathrm{P}=0.0 \mathrm{I}) ; \mathrm{I}^{2}=80 \%$

Test for overall effect: $Z=0.98(P=0.33)$

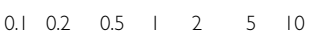

Favours Plasma Favours Recombinant 


\section{Analysis 2.2. Comparison 2 Recombinant vaccine versus plasma vaccine, Outcome 2 Full and partial}

seroconversion to anti-HBs.

Review: Hepatitis B vaccination for patients with chronic renal failure

Comparison: 2 Recombinant vaccine versus plasma vaccine

Outcome: 2 Full and partial seroconversion to anti-HBs

Study or subgroup Recombinant vaccine Plasma vaccine

\begin{tabular}{ccc} 
& $\mathrm{n} / \mathrm{N}$ \\
\hline Jungers 1994a & $48 / 60$ & $40 / 6$
\end{tabular}

Seaworth 1988a $\quad 12 / 20 \quad 7 / 10$

Seaworth 1988b 10/21 7/10

Total (95\% CI)

101

80

\begin{tabular}{|c|c|c|}
\hline $\begin{array}{c}\text { Risk Ratio } \\
\text { M- } \\
\text { H,Random,95\% } \\
\text { Cl }\end{array}$ & Weight & $\begin{array}{c}\text { Risk Ratio } \\
\text { M- } \\
\text { H,Random,95\% } \\
\text { Cl }\end{array}$ \\
\hline$F$ & $52.4 \%$ & $1.20[0.96,1.49]$ \\
\hline 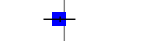 & $25.5 \%$ & $0.86[0.50,1.47]$ \\
\hline$\rightarrow$ & $22.1 \%$ & $0.68[0.37,1.25]$ \\
\hline$\bullet$ & $100.0 \%$ & $0.97[0.69,1.38]$ \\
\hline
\end{tabular}

Total events: 70 (Recombinant vaccine), 54 (Plasma vaccine)

Heterogeneity: $\mathrm{Tau}^{2}=0.05 ; \mathrm{Chi}^{2}=3.88, \mathrm{df}=2(\mathrm{P}=0.14) ; \mathrm{I}^{2}=48 \%$

Test for overall effect: $Z=0.16(P=0.87)$

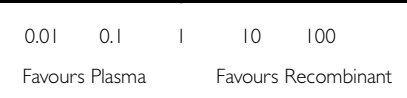


Analysis 2.3. Comparison 2 Recombinant vaccine versus plasma vaccine, Outcome 3 Sensitivity analysis for anti-HBs seroconversion - combining both recombinant arms of Seaworth 1988.

Review: Hepatitis B vaccination for patients with chronic renal failure

Comparison: 2 Recombinant vaccine versus plasma vaccine

Outcome: 3 Sensitivity analysis for anti-HBs seroconversion - combining both recombinant arms of Seaworth 1988

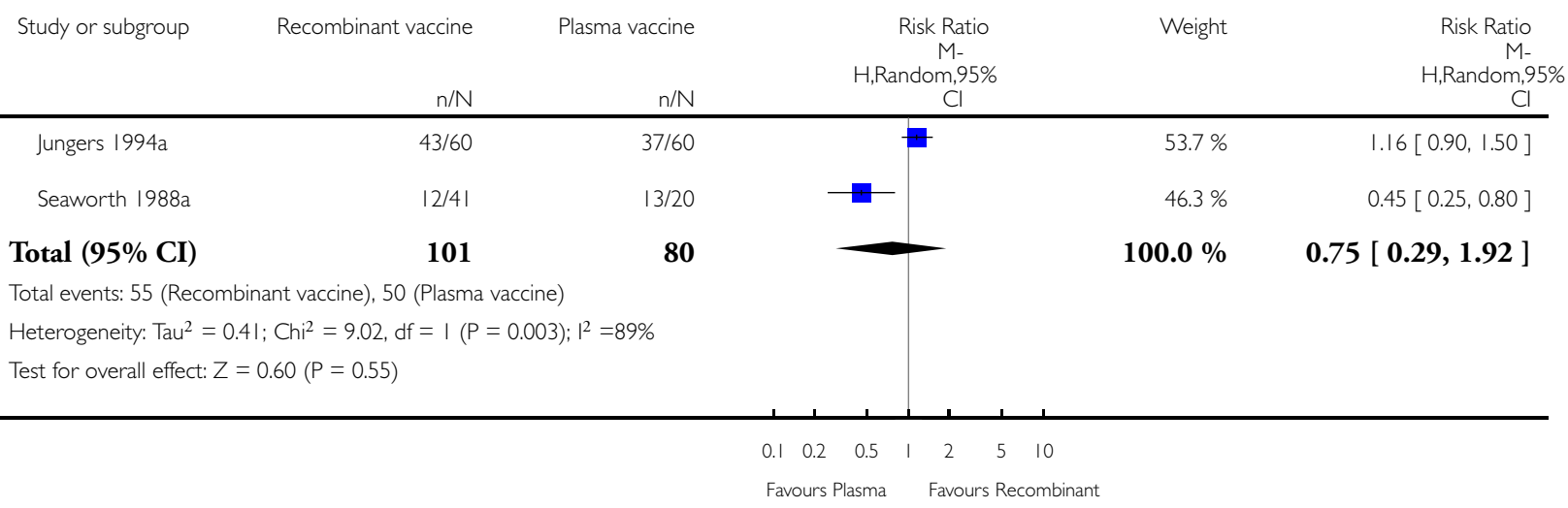

Analysis 2.4. Comparison 2 Recombinant vaccine versus plasma vaccine, Outcome 4 Sensitivity analysis for anti-HBs seroconversion (excluding the low dose recombinant arm of Seaworth 1988).

Review: Hepatitis B vaccination for patients with chronic renal failure

Comparison: 2 Recombinant vaccine versus plasma vaccine

Outcome: 4 Sensitivity analysis for anti-HBs seroconversion (excluding the low dose recombinant arm of Seaworth 1988)

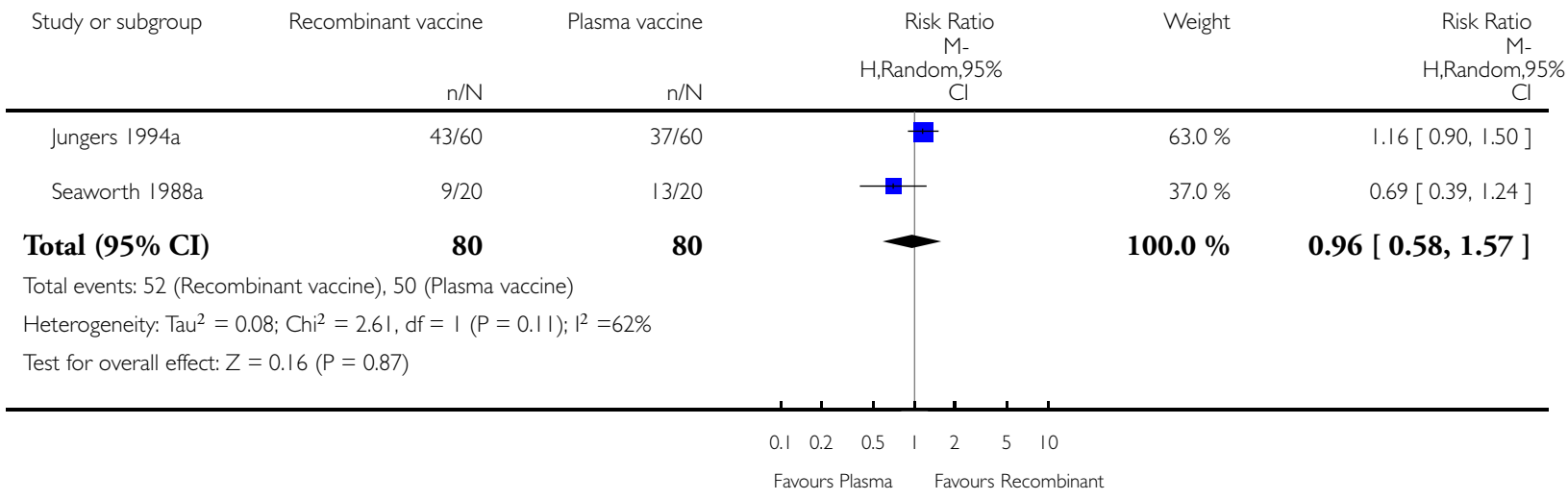

Hepatitis B vaccination for patients with chronic renal failure (Review)

Copyright $\odot 2009$ The Cochrane Collaboration. Published by John Wiley \& Sons, Ltd. 


\section{Analysis 3.1. Comparison 3 Reinforced recombinant vaccination series versus primary recombinant}

vaccination series, Outcome I Seroconversion to anti-HBs.

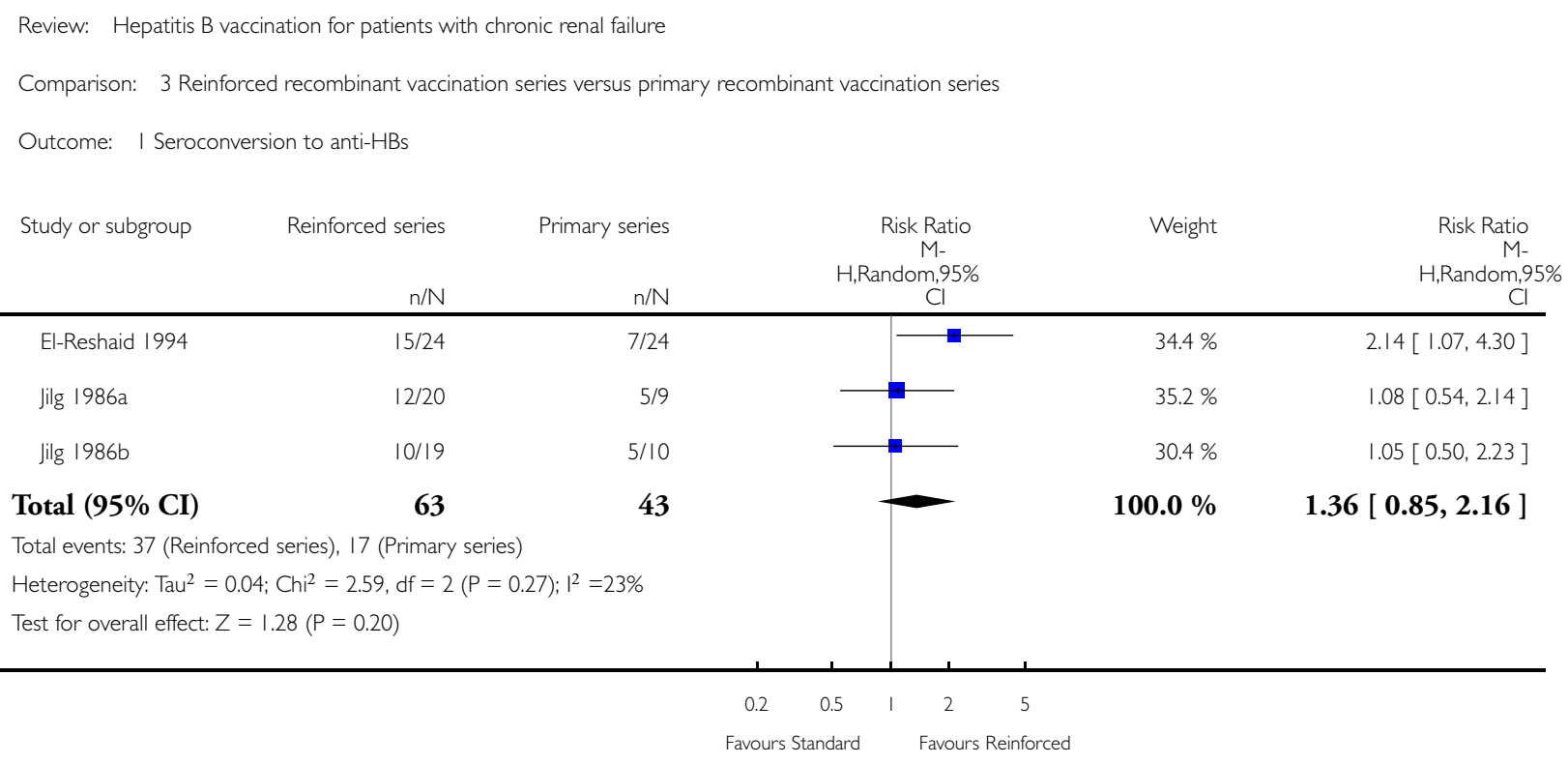

\section{ADDITIONAL TABLES}

Table 1. Criteria for assessing anti-HBs response (North America)

\begin{tabular}{l|ll}
\hline Response & Sample ratio units (SRU) & International units (IU/L) \\
\hline Inadequate & $2.1-9.9$ SRU & $2.1-9.9 \mathrm{IU} / \mathrm{L}$ \\
\hline Adequate & $>10 \mathrm{SRU}$ & $>10 \mathrm{IU} / \mathrm{L}$ \\
\hline
\end{tabular}


Table 2. Criteria for assessing anti-HBs response (Europe)

\begin{tabular}{|c|c|c|}
\hline Response & Sample ratio units (SRU) & International units (IU/L) \\
\hline Inadequate & $2.1-9.9$ SRU & $2.1-9.9 \mathrm{IU} / \mathrm{L}$ \\
\hline Low response & & $10-100 \mathrm{IU} / \mathrm{L}$ \\
\hline Adequate & $>10 \mathrm{SRU}$ & $>100 \mathrm{IU} / \mathrm{L}$ \\
\hline
\end{tabular}

Table 3. Methodological quality of included studies

\begin{tabular}{|c|c|c|c|c|}
\hline Included study & $\begin{array}{l}\text { Generation of allocation } \\
\text { sequence }\end{array}$ & Allocation concealment & Blinding & Follow-up \\
\hline Crosnier 1981 & Unclear - not described. & Unclear & $\begin{array}{l}\text { Adequate double blinded } \\
\text { and placebo controlled. }\end{array}$ & $\begin{array}{l}\text { Number and reason for } \\
\text { dropouts and withdrawals } \\
\text { mentioned. }\end{array}$ \\
\hline Desmyter 1983 & $\begin{array}{l}\text { Unclear - not described. A } \\
\text { code was used, however, } \\
\text { this was insufficient infor- } \\
\text { mation to determine ap- } \\
\text { propriateness }\end{array}$ & $\begin{array}{l}\text { Adequate. An indepen- } \\
\text { dent physician had sole ac- } \\
\text { cess to the code }\end{array}$ & $\begin{array}{l}\text { Adequate double blinded } \\
\text { and placebo controlled. }\end{array}$ & $\begin{array}{l}\text { Number and reason for } \\
\text { dropouts described. }\end{array}$ \\
\hline El-Reshaid 1994 & Unclear - not described. & Unclear & Not double blinded. & $\begin{array}{l}\text { Number of dropouts and } \\
\text { withdrawals given but not } \\
\text { reasons. }\end{array}$ \\
\hline Jilg 1986 & Unclear - not described. & Unclear & Not double blinded. & $\begin{array}{l}\text { Number and reasons for } \\
\text { dropouts and withdrawals } \\
\text { not reported }\end{array}$ \\
\hline Jungers 1994 & Unclear - not described. & Unclear & Not double blinded. & $\begin{array}{l}\text { Number and reasons for } \\
\text { dropouts and withdrawals } \\
\text { mentioned. }\end{array}$ \\
\hline Seaworth 1988 & Unclear - not described. & Unclear & Not double blinded. & $\begin{array}{l}\text { Number and reasons for } \\
\text { dropouts and withdrawals } \\
\text { described. }\end{array}$ \\
\hline Stevens 1984 & Unclear - not described. & Unclear & $\begin{array}{l}\text { Adequate double blinded } \\
\text { and placebo controlled. }\end{array}$ & $\begin{array}{l}\text { Number and reasons for } \\
\text { dropouts and withdrawals } \\
\text { described. }\end{array}$ \\
\hline
\end{tabular}


A P P E N D I CES

\section{Appendix I. Search Strategies}

\begin{tabular}{|c|c|c|}
\hline Database & Search strategy & Search performed \\
\hline $\begin{array}{l}\text { The Cochrane Hepato-Biliary Group Con- } \\
\text { trolled Trials Register }\end{array}$ & $\begin{array}{l}\text { ('renal failure' or 'kidney failure' or 'renal } \\
\text { disease' or 'kidney disease' or dialysis or } \\
\mathrm{h}^{*} \text { emodialysis) and 'hepatitis b' and (vac- } \\
\text { cin* or immun* or booster or re-vaccin* }^{*} \\
\text { or revaccin*) or (engerix or heptavax or re- } \\
\text { combivax) }\end{array}$ & October 2002 \\
\hline PubMed/MEDLINE MESH Terms & $\begin{array}{l}\text { kidney[MESH]; dial- } \\
\text { ysis[MESH]; dialysis[MESH], peritoneal } \\
\text { dialysis, continuous ambulatory[MESH]; } \\
\text { dialysis, peritoneal[MESH]; kidney failure, } \\
\text { chronic[MESH\}; kidney failure[MESH]; } \\
\text { uremia[MESH]; hepatitis B[MESH]; hep- } \\
\text { atitis B surface antigens[MESH]; anti- } \\
\text { gens, surface[MESH]; hepatitis B core } \\
\text { antigens[MESH]; hepatitis B e anti- } \\
\text { gens[MESH]; hepatitis B surface anti- } \\
\text { gens[MESH]; vaccine[MESH]; hepatitis } \\
\text { B vaccines[MESH]; vaccination[MESH]; } \\
\text { immunization, secondary[MESH]; im- } \\
\text { munity[MESH]; immune sera[MESH]; } \\
\text { vaccine, hepatitis B[MESH]; adjuvants, } \\
\text { immunologic[MESH]; adjuvants, phar- } \\
\text { maceutic[MESH]; randomized controlled } \\
\text { trial[MESH] }\end{array}$ & July 2003 \\
\hline
\end{tabular}

PubMed/MEDLINE Search Strategy

(renal OR kidney OR kidney[MESH] July 2003

OR "renal dialysis" [MESH] OR dialysis

OR dialysis[MESH] OR hemodialysis OR

haemodialysis OR CAPD OR "continuous

ambulatory peritoneal dialysis” OR CCPD

OR "continuous cyclical peritoneal dialysis" OR ESRD OR "end stage renal disease" OR "chronic renal failure" OR "renal failure" OR ESRF OR "end stage renal failure" OR "chronic renal insufficiency" OR "renal insufficiency" OR "peritoneal dialysis, continuous ambulatory" [MESH] OR "dialysis, peritoneal" [MESH] OR "kidney failure, chronic" [MESH] OR "kidney failure" [MESH] OR uremia OR uraemia OR uremic OR uremia[MESH]) AND ( "hepatitis b" OR "hepatitis B" [MESH] 
OR "australian antigen" OR HBSAG OR "surface antigen" OR "hepatitis b surface antigens" [MESH] OR "antigens, surface" [MESH] OR "hepatitis b core antigens"[MESH] OR "hepatitis b e antigens" [MESH] OR "hepatitis b surface antigens”[MESH]) AND ( vaccine[MESH] OR vaccin* OR immun* OR booster OR "re-vaccinat*" OR revaccinat* OR engerix OR heptavax OR recombivax OR "hepatitis b vaccines" [MESH] OR "secondary vaccination" OR "viral vaccines" [MESH] OR "viral hepatitis vaccines" [MESH] OR vaccination[MESH] OR "immunization, secondary”[MESH] OR immunity[MESH] OR “immune sera" [MESH] OR "vaccine, hepatitis b” [MESH] OR adjuvant* OR "Adjuvants, Immunologic"[MESH] OR "Adjuvants, Pharmaceutic"[MESH]) AND ("trial” OR "clinical trial” OR "randomized controlled trial" OR "randomised controlled trial" OR "randomized controlled trial" [MESH] OR "randomized controlled trial.pt” OR review[pt]) subheadings

\#2 explode "chronic-kidney-failure"/ all subheadings \#3 explode "kidney"/ all subheadings \#4 explode "kidney-disease"/ all subheadings

\#5 explode "kidney-failure"/ all subheadings

\#6 explode "hemodialysis"/ all subheadings

\#7 explode "continuous-ambulatory-peritoneal-dialysis"/ all subheadings

\#8 explode "dialysis"/ all subheadings \#9 explode "peritoneal-dialysis"/ all subheadings

\#10 explode "uremia"/ all subheadings

\#11 (renal or kidney) and (failure or disease* or insufficien*)

\#12 ur*emi*

\#13 dialys*

\#14 $\mathrm{h}^{*}$ emodialys*

\#15 CAPD or CCPD or ESRD or ESRF

$\# 16 \# 1$ or \#2 or \#3 or \#4 or \#5 or \#6 or \# 
7 or $\# 8$ or $\# 9$ or $\# 10$ or $\# 11$ or $\# 12$ or $\# 13$ or \#14 or \#15

\#17 explode "hepatitis-B"/ all subheadings \#18 explode "hepatitis-B-antigen"/ all subheadings

\#19 explode "hepatitis-B-core-antigen"/ all subheadings

\#20 explode "hepatitis-Be-antigen"/ all subheadings

\#21 explode "hepatitis-B-surface-antigen"/ all subheadings

\#22 hepatitis B

\#23 australian antigen

\#24 HBsAg

$\# 25$ surface antigen*

\#26 \#17 or \#18 or \#19 or \#20 or \#21 or \# 22 or \#23 or \#24 or \#25

\#27 explode "hepatitis-B-vaccine"/ all subheadings

\#28 explode "vaccine"/ all subheadings

\#29 explode "vaccination"/ all subheadings \#30 explode "immunization"/ all subheadings

\#31 explode "immunity"/ all subheadings \#32 explode "antiserum"/ all subheadings \#33 vaccin* or immun* or booster or re*vaccin*

\#34 \#27 or \#28 or \#29 or \#30 or \#31 or \# 32 or \#33

\#35 \#26 and \#34

\#36 energix or heptavax or recombivax

\#37 \#35 or \#36

\#38 \#16 and \#37

\#39 random* or blind* or placebo or metaanalysis

\#40 \#38 and \#39

\section{WHAT'S NEW}

Last assessed as up-to-date: 23 May 2004. 


\begin{tabular}{l|l|l}
\hline Date & Event & Description \\
\hline 9 November 2008 & Amended & Converted to new review format. \\
\hline
\end{tabular}

\section{H I S T O R Y}

Protocol first published: Issue 3, 2002

Review first published: Issue 3, 2004

\section{CONTRIBUTIONS OF AUTHORS}

RJS, CAH, JZ, JU, and AN developed the protocol and undertook data extraction of included trials.

RJS, CAH, JZ, and JU undertook final analysis and revisions of the review.

SPT and MEKM advised on methodology and review process.

\section{DECLARATIONSOF INTEREST}

None known.

\section{SOURCES OF SUPPORT}

\section{Internal sources}

- Canadian Cochrane Centre Network - University of Manitoba Site Group - Dr. Michael EK Moffatt, Canada.

\section{External sources}

- No sources of support supplied

\section{INDEX TERMS}

\section{Medical Subject Headings (MeSH)}

Hepatitis B [immunology; * prevention \& control]; Hepatitis B Vaccines [*administration \& dosage; immunology]; Kidney Failure, Chronic [ ${ }^{*}$ complications]; Randomized Controlled Trials as Topic 


\section{MeSH check words}

Humans

Copyright @ 2009 The Cochrane Collaboration. Published by John Wiley \& Sons, Ltd. 